\title{
POLÍTICAS DE DESARROLLO REGIONAL EN MÉXICO
}

\author{
LUIS UNIKEL * \\ El Colegio de México
}

\section{INTRODUCCIÓN}

TERRitorialmente hablando, el desarrollo socioeconómico no ocurre de modo uniforme; se produce con mayor intensidad en unos lugares que en otros, lo cual genera desigualdades regionales. El fenómeno es mundial; de hecho no hay país, sea industrializado o no, de economía mixta o centralmente planificada que no presente disparidades regionales en el ingreso per capita, en el nivel de vida de la población y, en general, en la distribución de la riqueza nacional. Sin embargo, los países de economía capitalista observan mayores desequilibrios regionales que aquellos con sistemas socialistas y, en forma más aguda, entre los primeros, los llamados países subdesarrollados, tales como los de América Latina. ${ }^{1} \mathrm{Y}$

* El autor, como investigador visitante en el Centre for Environmental Stuldies de Londres en 1974-1975, gozó de una beca del British Council y de una subvención para investigación del Joint Committee de Estudios Latinoamericanos del American Council of Learned Societies y del Social Science Research Council Agradece la ayuda recibida del Arq. Francisco Covarrubias en la obtención de una parte del material utilizado así como sus comentarios al trabajo.

1 Como ilustración de lo anterior, se asevera que los mayores problemas regionales de Polonia pueden considerarse resueltos. Asimismo, los desequilibrios regionales de Checoslovaquia, Yugoslavia, Hungría y otros países socialistas, han sido reducidos de manera significativa durante los últimos dos decenios. En comparación con los países de Europa oriental, algunos de los más avanzados de Europa occidental, tales como Francia y en particular Italia, manifiestan importantes disparidades territoriales en términos de ingreso medio, índice de desempleo, tasa de emigración, calidad de la infraestructura disponible y subutilización de recursos naturales. Véanse, respectivamente: F. E. Ian Hamilton, Poland's Western and Northern Territories, Londres, Oxford University Press, 1975, p. 7; B. Winiarski, The Programming and Development Policy of Backward Areas in National Economic Planing in Poland, en E. A. G. Robinson (Comp.) Backward Areas in Advanced Countries, Londres, MacMillan, 1969, pp. 243-339, y pp. 62-239; así como European Communities, Report on the Regional Problems in the Enlarged Conmunity, Com. (74), 550 final, Bruselas, 1973; Lloyd Rodwin, Nations and Cities, Boston, Mass. Houghton Mifflin Co., 1970, pp. 156-216; G. Ross y S. Cohen, The Politics of French Regional Planning, The John Hopkins University Center, Baltimore, Maryland; Alan Mountjoy, The Mezzogiomo, Londres, Oxford University Press, y otros más. 
lo que es más significativo, en éstos las desigualdades regionales se dan a niveles de ingreso per capita inferiores a los de las regiones pobres de los países europeos. ${ }^{2}$

Para ilustrar las diferencias interregionales en América Latina bastan unas cuantas cifras. Estimaciones hechas con el ingreso máximo regional per capita en relación con el ingreso mínimo per capita (alrededor de los años sesenta) muestran que la mayoría de los países tienen disparidades de 1: 10 (entre sus unidades subnacionales más pobres y las más ricas). En los extremos aparecen países tales como Guatemala, con una disparidad de 1: 37 entre el departamento más pobre y el más rico; $\mathrm{y}$, en el otro, Chile con una relación de 1: $5 .^{3}$

Otro hecho característico de América Latina, indicativo de la existencia de grandes desigualdades regionales, es lo que se conoce por alta primacía del sistema de ciudades, comúnmente conocido por macrocefalia. ${ }^{4}$ Este fenómeno se caracteriza por la elevada concentración de población y de actividades socioeconómicas en una sola ciudad -0 en dospor lo general la capital nacional. Por ejemplo, en 1960 Buenos Aires concentraba no sólo el $34 \%$ de la población nacional sino también, junto con Rosario, los dos tercios de la producción industrial del país. ${ }^{5}$ En México, la zona metropolitana de la ciudad de México absorbía en 1965 el $16 \%$ de la población nacional, el $45 \%$ del valor agregado industrial del país y el $62.6 \%$ de la inversión nacional en educación superior. ${ }^{6}$

Las cifras anteriores no son más que reflejo de la situación de atraso socioeconómico en que vive gran parte de la población de América Latina, en particular aquella que habita zonas rurales. También implican

2 Por ejemplo, Italia, país que presenta las mayores desigualdades regionales de la Europa industrial, registró en 1950 un ingreso per capita en el Mezzogiorno de 150 dólares (1 800 pesos). Brasil tenía en 1947 estados como Maranhão, con 74 dólares per capita y 11 estados, de un total de 21, por debajo de los 150 dólares. Aún en 1966 todavía cinco estados registraban ingresos per capita inferiores a 150 dólares. Estas cifras, aunque no son del todo comparables, ilustran el punto. Véase, P. Saraceno, Development Policy in an Over-populated Area: Italy's Experience, en E. A. G. Robinson, op. cit., p. 226; y Alan Gilbert, Latin American Development; A Geographic Perspective, Londres, Penguin Books, 1974, p. 222.

3 Walter Stohr, El desarrollo regional en América Latina: experiencias y perspectivas, Buenos Aires, Argentina, Ediciones SIAP, 1972, gráfica 6, p. 179. Entre los estudios adicionales que proporcionan cifras sobre disparidades regionales o que permiten elaborarlas están: Ricardo Carrillo Arronte, "La estrategia del desarrollo regional de México: evolución, magnitud y perspectivas", en M. Wionezek (Comp.), La sociedad mexicana: presente y futuro, México, Fondo de Cultura Económica, 1974, p. 420, y A. Gilbert, op. cit., pp. 224 y 226.

4 Rubén Utria, Una política de desarrollo regional y urbano en función de la realidad latinoamericana, IX Congreso Interamericano de Planificación, Bogotá, septiembre de 1972, pp. 21 y 22.

5 Alan Gilbert, "Notas Introductorias sobre disparidades regionales en América Latina", mecanografiado, 1975, p. 2.

6 Alan Lavell, "Regional Industrialization in Mexico: Some Policy Considerations", en Regional Studies, Vol. 6, 1972, p. 345. 
que, al lado de estas áreas pobres, coexisten unas cuantas regiones más desarrolladas, en general las que contienen los principales centros urbanos de los países y las pocas zonas agrícolas de alta mecanización. Es en estas regiones, principalmente en las ciudades, donde la accesibilidad a mercados amplios y diversificados de consumo, de mano de obra y de capital; disponibilidad de buenas comunicaciones y transportes, así como de una infraestructura y servicios generados por el crecimiento económico de acuerdo con un patrón de capitalismo subdesarrollado, han sido aprovechadas por los intereses económicos y políticos nacionales así como locales que han considerado favorable la realización de inversiones, tanto del sector gubernamental como del empresarial, ya sea en beneficio público como privado, y han generado mayor crecimiento industrial y económico en general. El resultado ha sido, dicho en pocas palabras, la acumulación progresiva de capital en unos cuantos lugares y en unas cuantas manos. Se ha registrado un crecimiento económico nacional, es indudable, pero también lo es el elevado costo social que ha exigido.

\section{Factores DETERMINANTES DE LAS Disparidades REgIONALES Y DE LA MACROCEFALIA}

La explicación del origen de las disparidades regionales en América Latina es una parte importante de la explicación global de su atraso socioeconómico. Existe acuerdo en considerar que el crecimiento de las áreas denominadas centrales (las de mayor nivel de desarrollo y dinamismo socioeconómico) están subsidiadas por la periferia (el territorio restante). Sin embargo, a partir de este punto, las opiniones sobre las causas y las consecuencias de tal transferencia de recursos difieren y van desde la teoría neoclásica que dice que esto puede interpretarse como "... la movilización de capital necesario para financiar el despegue industrial [en el centro]" o bien que la culpa de los problemas, tanto los que resultan de las disparidades regionales como del gran tamaño de las metrópolis nacionales, puede atribuirse al progreso social y económico de los países. ${ }^{7}$

En el otro extremo de las opiniones encontramos un número creciente de cientistas sociales y técnicos en planificación urbana y regional que concuerdan en apoyar la tesis explicativa del "colonialismo interno", según el cual "... una o pocas regiones centrales de cada país crecen y se desarrollan a costa del estancamiento de las demás ..." 8 y que

7 Rodwin, op. cit., p. xi.

8 Utria, op. cit., p. 9. A este respecto la teoría está más desarrollada que el análisis empírico que fundamenta la tesis según la cual la región preminente impide $u$ obstaculiza el crecimiento de las demás. Sin embargo, empieza a demostrarse que la esperada difusión territorial del desarrollo económico a partir de grandes centros urbanos, de rápido crecimiento y economía dinámica, no ha ocurrido. Tal es el caso de Antioquía, Colombia, demostrado en el trabajo de Alan Gilbert, $A$ Note on the Incidence of Development in the Vicinity of a Growth 
este proceso forma parte integral del sistema de dependencia de los paises de América Latina con respecto a los centros hegemónicos a escala internacional. $^{9}$

En términos globales, la generación de disparidades regionales se puede atribuir a la conjugación de una serie de factores geográficos, históricos y, principalmente, de economía política. En primer lugar, es indiscutible la influencia ejercida por la distribución geográfica irregular de los recursos naturales, así como la de los accidentes geográficos que condicionan diferencias climáticas y de las características ecológicas y culturales de la población. En segundo lugar, los países ocupan, debido a circunstancias históricas y políticas, territorios de distintas extensiones de superficie, que disponen de uno o varios recursos naturales, en cantidad abundante o escasa, de calidad alta o baja, de accesibilidad y explotación fácil o difícil. Y, en tercer lugar, destacan los intereses económicos y políticos que ejercen la iniciativa privada o el estado en el control y manejo de los factores de la producción (capital, tierra y mano de obra), tanto en la ciudad como en el campo. A este respecto, es indudable que no obstante la innegable influencia que ejercen los factores geográficos e históricos en la generación de disparidades regionales, son las formas de producción y de apropiación de los recursos productivos así como las instituciones y las relaciones sociales y políticas que se derivan de ellas, los factores que explican en mayor medida el esquema de ccupación del territorio. ${ }^{10}$

En sentido histórico las desigualdades regionales en América Latina empiezan a acentuarse a partir y como consecuencia directa del modo de producción capitalista. ${ }^{11}$ Singer asevera que el desarrollo capitalista trae consigo un sesgo notable a favor de la ciudad en perjuicio del cam-

Center (en prensa). También puede observarse en el caso de las cinco principales ciudades de la India, véase Richard Ellefsen, "City-Hinterland Relationships in India", en Roy Turner (Comp.), India's Urban Future, Berkeley, Calif., University of California Press, 1963. Otros estudios realizados para los casos de Arequipa, Perú; en una ciudad de Nigeria y en Kuala Lumpur, llegan a conclusiones semejantes. Ésta, sin ser una prueba directa del obstáculo que al desarrollo constituye la gran ciudad, sí indica que está asociada con el subdesarrollo de la periferia contigua.

9 La literatura sobre dependencia y colonialismo interno es ya vasta, particu. larmente la publicada en español. Uno de los trabajos que explica con claridad este proceso es el de T. Dos Santos, "The Crisis of Development Theory and the Problem of Dependence in Latin America", en Henry Bernstein (Comp.), Underdevelopment and Development, Londres, Penguin Books, 1973, pp. 78-79. En el mismo libro véase, Celso Futado, "Elements of a Theory of Underdevelopment. The Underdeveloped Structure", pp. 33-43.

10 Utria, op. cit., p. 4.

11 Carlos Acedo Mendoza, Incidencia de los desequilibrios regionales internos en la marginalidad social, rural y urbana, Documento de referencia Núm. 11, Seminario sobre Aspectos Sociales del Desarrollo Regional, CEPAL-ILPES, noviembre de 1969, citado por Utria, op. cit., pp. 35-36; David Barkin (Comp.), ¿Quienes son los beneficiarios del desarrollo regional?, México, SEP/Setentas, Núm. 52, 1973 , p. 154. 
po. Añade que la ciudad latinoamericana, desde su etapa colonial hasta la comercial, ha tenido que dominar y depender del campo para subsistir, y que no fue sino hasta el nacimiento y la expansión industrial, cuando la ciudad se volvió productiva por vez primera desde la Conquista. Sólo a partir de entonces se establece una verdadera división del trabajo entre ciudad y campo, pero viciada por las relaciones de explotación preexistentes. Estos mecanismos de explotación y de transferencia del excedente del campo a la ciudad se han mantenido porque la industrialización, en la mayoría de los países de América Latina, sólo fue producto del reacomodo de la antigua estructura de dominación a las nuevas condiciones socioeconómicas y políticas y no de una verdadera transformación. ${ }^{12}$

Es dentro de este marco específico de desarrollo capitalista que se ha producido en América Latina una urbanización —entendida ésta como el proceso de la concentración progresiva de la población y de las actividades económicas en los centros urbanos- que se manifiesta generalmente por fenómenos de macrocefalia, pero fundamentalmente por agudas disparidades regionales.

Este tipo de urbanización no es reciente, pues en casos como los de México, Perú y Argentina, sus capitales ejercían un dominio indiscutible desde la época colonial y se notaban ya desigualdades regionales. Sin embargo, en su forma y magnitud actual, sí es producto de fenómenos acontecidos desde fines del siglo xix y, de manera principal durante este siglo. A excepción de los países del cono sur, la urbanización da muestras de intensificarse a partir del período 1914-1930, en que la ciudad inicia cierto proceso de industrialización vía la sustitución de importaciones. Esta política se ve reforzada durante y por los efectos de la depresión económica mundial de los años treinta, al contraerse la demanda de las exportaciones que sustentaban las economías de América Latina. Este hecho hizo surgir entre los gobiernos de la región la necesidad de depender menos de un modelo económico basado exclusivamente en las exportaciones, y de buscar una mayor independencia económica ampliando la intervención estatal interna. ${ }^{13}$

La segunda Guerra Mundial, al interrumpir en los países industriales la producción de bienes de consumo que América Latina importaba, favoreció aún más la implantación de una política de industrialización basada en la sustitución de importaciones. La inversión extranjera, en especial la norteamericana, se introdujo en la región con la intención de mantener el abastecimiento del mercado latinoamericano, pero ahora des-

12 Paulo Singer, Campo y ciudad en el contexto histórico latinoamericano, traducción del portugués que apareció originalmente en Cuadernos CEBRAP, Núm. 7 , São Paulo, 1972.

13 Harley Browning, "Primacy Variations in Latin America During the Twentieth Century", XXXIX Congreso Internacional de Americanistas, El proceso de urbanización en América desde sus orígenes hasta nuestros días, Lima, agosto de 1972. 
de el interior de los propios países. Se dedicó, en gran medida, al ensamblaje de partes importadas con otras que empezaban a producirse nacionalmente, proceso que se beneficiaba mayormente de la cercanía al principal mercado de consumo de las grandes ciudades.

De 1940 en adelante la ciudad exige mayor atención que el campo. Los intereses económicos y políticos, tanto de los grupos empresariales como del gobierno, se concentran en la ciudad y, muy particularmente, en las que se industrializan, ya que proporcionan mayores posibilidades de beneficio personal y de crecimiento rápido de la economía nacional.

La gran ciudad, a través de los ininterrumpidos y crecientes gastos públicos federales, así como de los subsidios directos e indirectos que el empresario industrial ha recibido del sector público, ha generado una serie de ventajas para la localización industrial, comercial y de servicios que, en combinación con el acelerado ritmo de crecimiento de la población registrado de 1940 a 1970 y de la cuantiosa migración ruralurbana, han conformado un patrón de urbanización de alta primacía y enormes disparidades regionales.

\section{LA MACROCEFALIA EN AMÉRICA LATINA}

Si se hace a un lado la discusión, hoy día superada, de la imposibilidad de establecer un solo tamaño óptimo de población para las ciudades, ${ }^{14}$ la cuestión central consiste en determinar si los costos económicos, sociales y políticos que genera la ciudad multimillonaria superan los beneficios respectivos. En términos generales, se desea saber si la ciudad preeminente, producto del proceso de crecimiento económico y de los intereses de los grupos que controlan los medios de producción, principalmente en países de economía capitalista, constituye un obstáculo o un factor promotor del desarrollo socioeconómico nacional y regional. ${ }^{15}$ Sería largo plantear los argumentos que distintos autores dan a favor o en contra. ${ }^{16}$ Richardson, en el intento más reciente y completo de sintetizar y analizar tales argumentos, tanto los que él llama "pesimistas"

14 Harry W. Richardson, The Economics of Urban Size, Londres, Saxon House, 1973, pp. 11 y 120-131, ofrece suficientes argumentos para desechar tal pretensión. 15 Vale la pena hacer la distinción entre la macrocefalia y el hecho de que la ciudad primaria sea de gran tamaño, pues los fenómenos no son coincidentes. Existen países de muy elevada macrocefalia como Guatemala y Uruguay donde la ciudad primaria no es una gran metrópoli en tamaño de población y por lo tanto no manifiesta la misma agudeza de problemas que los que presentan las ciudades primarias en países de menor macrocefalia como México y Argentina, o en países no macrocefálicos como Brasil o los Estados Unidos. Es claro que la macrocefalia refuerza la dinámica de concentración de la población y las activi. dades económicas, pero lo que más preocupa en cuanto a problemas urbanos es el gran tamaño $\mathrm{y}$, en relación a las disparidades regionales, la centralización del poder económico y político.

16 Gilbert hace un resumen claro sobre los argumentos a favor y en contra, en su libro, Latin American Development, op. cit., pp. 96-101. El tema lo trata con más amplitud $\mathrm{H}$. Richardson, así como otros autores. 
-quienes piensan que las grandes ciudades generan beneficios sociales netos negativos-, como de los "optimistas" o de los "no comprometidos", dice que los primeros se apoyan en argumentos sociopsicológicos o sociológicos nebulosos, mucho más difíciles de probar que los económicos, los cuales también presentan graves limitaciones para su medición. ${ }^{17}$ Asimismo, sostiene que "... la evidencia que se tiene sobre las variaciones de las externalidades, según el tamaño de las ciudades, es inconexo, parchado e incompleto y presenta problemas insuperables de ponderación. La mayor parte de la literatura ha sobreenfatizado las deseconomías. Mucho más rudimentaria ha sido la evaluación de las economías externas ... que son muy difíciles de cuantificar". ${ }^{18}$

Para el caso de América Latina, son pocos los llamados "optimistas". Son tantos los problemas que padecen las grandes metrópolis latinoamericanas que difícilmente hay quienes apoyen la idea de que éstas deben seguir creciendo. A lo más que se ha llegado es a defender a la gran ciudad de los repetidos ataques que se le hacen, si no en los términos de poner en tela de juicio tesis negativas sobre la metrópoli latinoamericana ${ }^{19}$ sí en argumentar que: "... [muchas de las críticas] cometen el error de atribuir la elevada primacía a una ciudad, en lugar de verlo como una característica del sistema socioeconómico y político nacional. ${ }^{20}$ Por otro lado, Browning asevera que es difícil comprobar que la ciudad preeminente es parásita, o sea que consume más de lo que produce. De hecho es tanto como afirmar que el crecimiento económico hubiera sido más rápido si no hubiera existido la elevada primacía. Sin embargo, aun defensores de la gran ciudad como Browning, que aseveran que en las primeras etapas del crecimiento económico de los países de América Latina la alta primacía ha cumplido una importante función generatriz, se sienten forzados a decir, por carecer de evidencias, que en etapas subsecuentes de tal crecimiento, la macrocefalia "... constituye una carga sobre la economía y la sociedad".21

Por lo tanto, la decisión a favor o en contra de la elevada primacía sólo puede hacerse en términos sociales o ideológicos, pues no puede resolverse por la simple diferencia entre ganancias o pérdidas econó. micas. ${ }^{22}$

Singer es de los pocos investigadores que en América Latina pone en tela de duda el grado de desproporción del tamaño de las grandes ciudades preeminentes de América Latina al preguntar: ¿qué tan grande es lo grande? ¿en qué límites la preponderancia de la metrópoli resulta

17 Ibid., p. 2.

18 Ibid., p. 118.

19 Ramiro Cardona y A. Simmons, apuntes sobre La crisis en las grandes ciudades en América Latina, Conferencia Sobre la Ciencia y el Hombre en las Américas, México, junio de 1973.

20 Harley Browning, op. cit., p. 73.

21 Ibid., p. 73.

22 A. Gilbert, Latin American Development, op. cit., p. 99. 
"desproporcionada"? ${ }^{23}$ Singer llega al extremo, respecto a lo que se dice generalmente sobre América Latina: “... la concentración urbana y la primacía metropolitana son falsos problemas, en la medida en que su eventual 'corrección' demanda apenas un cierto perfeccionamiento del aparato de planificación territorial, en los límites del sistema". ${ }^{24}$

Esta última aseveración, la más discutible de todas, es una muestra de la falta de consenso alrededor de una de las cuestiones más debatidas hoy en día, tanto en países atrasados como adelantados, y que se resumen en un dilema aparente o real entre la eficiencia y la justicia social o equidad, entre un crecimiento económico nacional más rápido y una mejor distribución territorial y personal del ingreso; entre mantener un modelo de desarrollo económico "desarrollista": "crecimiento del PIB a toda costa", o bien perseguir el crecimiento y la redistribución territorial y personal más equitativa del producto nacional.

En suma, tal parece que la evidencia disponible, teórica y empírica, no permite comprobar categóricamente que la ciudad primaria es "parásita": que cuesta económica y socialmente al país más de lo que le produce.

En el caso específico de México, mientras se resuelve la discusión teórica referente a los costos y beneficios de la gran ciudad en la economía nacional, así como el dilema aparente o real entre equidad y eficiencia o justicia social y crecimiento económico rápido, si es que se llegan a resolver, pienso que es necesario tomar una posición basada en valores sociales e ideológicos. Esta es la de intentar una política de desarrollo regional que reduzca las actuales disparidades territoriales y personales del ingreso y frene el crecimiento de la zona metropolitana de la ciudad de México. De allí que se considere indispensable dedicar mayores esfuerzos a enjuiciar de manera crítica los errores y aciertos de lo que han hecho los gobiernos mexicanos para generar el patrón de distribución de población y actividades económicas actuales como de los intentos por modificarlo, los objetivos perseguidos, los procedimientos aplicados y los resultados obtenidos, que a tratar de resolver las cuestiones anteriores.

Este trabajo tiene por objeto contribuir a esta tarea que otros autores han efectuado antes o que lo hacen en el presente, ${ }^{25}$ para lo cual, una vez

23 Paulo Singer, "Urbanización, dependencia y marginalidad en América Latina", en Martha Schteingart (Comp.), Urbanización y dependencia en América Latina. Buenos Aires, Ediciones SIAP, 1973, p. 103.

24 Ibid., p. 108.

25 Ante la imposibilidad de presentar una bibliografía completa de los trabajos, sólo presentaremos algunos de ellos que considero los más importantes: P. Lamartine Yates, El desarrollo regional de México, Banco de México, 1960; Fernando Zamora, Diagnóstico económico regional, Secretaría de Industria y Comercio, 1959; David Barkin y Timothy King, Desarrollo económico regional (enfoque por cuencas hidrológicas de México), México, Siglo XXI, 1970; J. Wilkie, The Mexican Revolution: Federal Expenditure and Social Change since 1910, Berkeley, University of California Press, 1967; Eliseo Mendoza, "Implicaciones regionales del 
hechos los planteamientos generales que conforman el marco teórico del cual se parte, se procederá a comentar las políticas regionales que han estado en vigencia antes y a partir de 1970, así como algunos de los instrumentos vigentes para lograrla. Este trabajo es una versión preliminar de uno más amplio que se realiza actualmente sobre este tema, a la luz de la experiencia acumulada por tres de los países europeos que mayores esfuerzos han hecho por aliviar sus problemas regionales: la Gran Bretaña, Francia e Italia.

\section{LAS disPaRIDADES REgIONALES Y LA MACROCEFALIA EN MÉxico}

En términos geográficos, México es un país de enormes contrastes geofísicos, climáticos, orográficos e hidrográficos. Manifiesta una distribución muy irregular de sus recursos' naturales (tierras de cultivo, agua, minerales, flora, etc.) la cual ha sido poco propicia para el desarrollo económico de ciertas regiones. Por ejemplo, mientras el Sureste contiene aproximadamente el $40 \%$ de los recursos hidrológicos del país, sólo tiene el $10 \%$, aproximadamente, de la población nacional.

Este excedente acuífero, más que un recurso, ha sido hasta no hace mucho tiempo, un obstáculo a su desarrollo. Por otro lado, el país posee grandes zonas áridas donde subsisten aproximadamente 8 millones de habitantes, o bien, grandes centros urbanos industriales como Monterrey, en medio de zonas áridas poco pobladas. Mientras el Noroeste y algunas zonas del Norte están relativamente bien dotadas de recursos naturales y población, partes del Bajío cuentan con un enorme potencial humano principalmente en las ciudades, pero escasos recursos o costosos de explotar para el desarrollo agrícola. O sea que el molde ecológico del país sólo ha favorecido el desarrollo de algunas regiones, pero no ha sido un obstáculo para que, con el apoyo gubernamental, otras zonas con pocos recursos naturales como la del Valle de México, crezcan aceleradamente.

desarrollo regional de México”, Demografía y Economía, El Colegio de México, Vol. III, Núm. 1, 1969; Ricardo Carrillo Aronte, "Ensayo analítico metodológico de planificación interregional en México", 1969, y "La estrategia del desarrollo regional de México; evolución, magnitud y perspectivas", en $M$. Wioncsek y otros autores, Disyuntivas sociales, presente y futuro de la sociedad mexicana, II, SEP/ Setentas, Núm. 5, 1972; Claude Bataillon, Las regiones geográficas en México, Siglo XXI, 1969 y La ciudad y el campo en el México central, Siglo XXI, 1972; Ángel Bassols B., México y la división económica regional, Escuela Nacional de Economía, UNAM, 1964; Luis Unikel y Edmundo Victoria, "Medición de algunos aspectos del desarrollo socioeconómico de las entidades federativas de México", Demografía y Economía, El Colegio de México, Vol. IV, Núm. 3, 1970; Claudio Stern, Las regiones de México y sus niveles de desarrollo socioeconómico, Jornada Núm. 72, El Colegio de México, 1973. Para obtener una bibliografía más amplia al respecto, consúltese Luis Unikel, "Bibliografía sobre desarrollo urbano y regional en México", Demografía y Economín, Vol. VI, Núm. 3, El Colegio de México, 1972, y diversos números de la publicación semanal, El mercado de valores, Nacional Financiera, 1973-1974. 
Desde el punto de vista histórico, ${ }^{26} \mathrm{y}$ en términos sintéticos, las desigualdades regionales en México, su macrocefalia urbana y, en general el presente patrón de asentamientos humanos, se empezaron a gestar desde la época colonial. Fue durante este largo período cuando el gobierno colonial estableció una importante red de centros urbanos, y cuando destacó la ciudad de México, capital y principal asiento económico, políticoadministrativo de la Nueva España. Esta metrópoli integra de tal modo el comportamiento de las diferentes regiones de la Colonia que a mediados del siglo xviII se percibe la existencia de un sistema urbano definido por los centros urbanos existentes a lo largo de las vías de comunicación entre las ciudades mineras del norte y la capital; los poblados asentados a lo largo de la ruta México-Veracruz, y el conjunto de ciudades de la zona del Bajío.

Al estallar la guerra de independencia experimentan algunas alteraciones temporales la hegemonía ejercida por la ciudad de México sobre el resto del país así como la permanencia del eje México-Veracruz como elemento clave de la economía. Pero al triunfo del movimiento insurgente se reinicia el proceso de centralización, y no fue sino hasta la época de la guerra entre México y Estados Unidos y de la Guerra de Secesión norteamericana cuando vuelven a cobrar auge algunos de los mercados mexicanos de carácter regional e incluso se desarrollaron algunos antes inexistentes. Todavía durante la primera etapa del Porfiriato, la expansión del mercado exterior, combinada con la creciente explotación minera y con el desarrollo de los puertos y los ferrocarriles nacionales, dio cabida al surgimiento de mercados regionales en centros urbanos del Norte y del interior del país.

Sin embargo, además de que esto no afectó la importancia relativa de la capital en la estructura del sistema urbano y regional del país, la orientación del nuevo sistema de transporte, el control de las finanzas públicas y el libre acceso de capitales extranjeros se conjugaron para dar lugar al proceso que definitivamente centralizó la vida nacional en la ciudad capital.

El movimiento revolucionario (1910-1921) contribuyó a concentrar en la ciudad de México la población y el capital que huía de las ciudades y del campo donde tenía lugar la lucha. Una vez concluida la etapa

26 Lo que tan sucintamente se ha expresado a manera de antecedentes o precondicionantes históricos de las disparidades regionales y de la macrocefalia en México, de hecho deben considerarse como una serie ininterrumpida de acontecimientos generados por procesos sociales, económicos y políticos, en distintas épocas de la evolución del país, desde la prehispánica a la presente. No son, por lo tanto, una secuencia cronológica de hechos inconexos, sino que existen relaciones de causa-efecto, territoriales y temporales, entre los distintos actores que han intervenido en la explotación de los medios de producción. Para un análisis de esta indole, véase P. Singer, "Campo y ciudad", op. cit. Para mayores detalles véase Luis Unikel, Crescencio Ruiz Chiapetto y Gustavo Garza, El desarrollo urbano en México, diagnóstico e implicaciones futuras, Centro de Estudios Económicos y Demográficos, El Colegio de México, 1974 (en prensa). 
revolucionaria e iniciada la "etapa constructiva", los gobiernos en el poder han propiciado, a través de la forma como se han distribuido territorialmente las inversiones pública y privada, el predominio de la ciudad de México y las desigualdades regionales. Durante esta "etapa" del desarrollo de México (1921-1970), los gobiernos federales sólo han cumplido parcialmente los objetivos de crear "... un aparato productivo que sea capaz de satisfacer las necesidades de sus habitantes dentro de niveles de justicia y bienestar".27 Se ha creado el aparato productivo pero no ha satisfecho todavía las necesidades de justicia y bienestar. Así, la industrialización basada en la sustitución de importaciones; el sistema tarifario en el transporte de productos primarios que ha favorecido la movilización de los primeros a los centros de consumo; la política de desarrollo agrícola que ha beneficiado a las zonas de agricultura moderna, mecanizada y de exportación; y otras medidas de política económica sectorial que a base de incentivos, subsidios y aranceles de diverso tipo han favorecido la concentración, en unas cuantas zonas del país, de la población, de las actividades socioeconómicas y culturales, así como del poder político, todo lo cual ha reforzado la estructura centralizada y regionalmente desigual. ${ }^{28}$

Los planteamientos generales de la primera parte del trabajo se aplican bastante de cerca al caso de México. Sin embargo, a continuación se presentan con un poco más de detalle algunos rasgos característicos.

Las enormes disparidades interregionales y sus múltiples implicaciones negativas a que se hace referencia han despertado el interés de investigadores nacionales y extranjeros, quienes han medido las disparidades regionales en términos absolutos y relativos y su dinámica de convergencia o divergencia, han hecho intentos por explicar las causas de dichos fenómenos y han enjuiciado las políticas y los programas de acción que el gobierno ha intentado para fomentar el desarrollo regional. ${ }^{29}$

Los resultados de los estudios muestran variaciones por la diversidad de regionalizaciones utilizadas ${ }^{30}$ y de procedimientos analíticos aplicados

27 R. Carrillo Arronte, op. cit., p. 415.

28 Para mayores detalles sobre el proceso de desarrollo regional de México, véanse: D. Barkin y T. King, op. cit., pp. 47-71, y P. Lamartine Yates, op. cit. 29 Algunos de estos estudios se señalan en la nota 25.

30 La mayoría de las veces los estudios regionales no son comparables entre sí debido a la diferencia en las unidades territoriales utilizadas. Por lo general, se analizan las entidades federativas, pero también se han hecho diversos estudios a partir de regionalizaciones del país con base en diferentes agrupaciones de entidades o de municipios que, en principio, conforman regiones geoeconómicas o presentan mayor homogeneidad interna y heterogeneidad externa, de acuerdo a una serie de características físicas, económicas y sociales, o bien atendiendo a la existencia de cuencas hidrológicas que no siguen ninguno de los límites político-administrativos existentes, sino los límites que observan los parteaguas de los principales ríos de la República. Para mayores detalles consúltese, Ángel Bassols B., Zonificación de México para fines de planeación económica y social, Secretaría de la Presidencia, 1965; Rafael Arias, tesis de licenciatura, Facultad de Economía, Universidad Veracruzana, Jalapa, Ver., 1973. A partir de 1975, 
para determinar el nivel relativo de desarrollo socioeconómico de las regiones y su cambio en el tiempo. Sin embargo, existe acuerdo en la selección de las entidades o regiones que ocupan las posiciones superiores e inferiores de la jerarquía. Entre las primeras generalmente están el Distrito Federal, solo o junto con el estado de México, así como todas o la mayoría de las entidades de la frontera norte. A la zaga siempre aparecen algunas de las siguientes: Tlaxcala, Guerrero, Oaxaca, Chiapas, Zacatecas, Hidalgo y Tabasco. Donde los estudios presentan mayores discrepancias es en la clasificación de las entidades federativas de nivel medio de desarrollo. Pero mayor desacuerdo aún se observa en la determinación de la dinámica de convergencia o divergencia de las disparidades regionales, fenómeno tanto o más importante que la propia situación relativa de la entidad o región, y cuya correcta apreciación constituye un dato clave en la formulación de políticas regionales.

Carrillo Aronte y Medellín ${ }^{31}$ han llegado a la conclusión de que las disparidades regionales en México han crecido, de 1950 a 1960 el primero, y de 1921 a 1960 el segundo, a excepción hecha de la región norte (estados de la frontera norte). Mendoza y Wilkie, por otro lado, concluyen que la brecha relativa entre entidades federativas se ha cerrado ${ }^{32}$ para el período 1940-1960, gradualmente de 1940 a 1950 y de manera significativa de 1950 a 1960.

En contraste con los resultados anteriores, un estudio del Centro de Estudios Económicos y Demográficos (CEED) ${ }^{33}$ muestra que en el período 1900-1970, desde el punto de vista de los procesos de urbanización y desarrollo económico, las disparidades regionales entre la región del Valle de México y las del Noroeste, Norte y Golfo están disminuyendo, mientras que con las del Centro-oeste y Sur y Sureste se mantienen prácticamente constantes. Asimismo, el distanciamiento de los dos grupos an-

México cuenta con una regionalización oficial para la programación del desarrollo económico y social del país, que lo divide en diez grupos de entidades federativas contiguas. La formulación fue realizada por la Secretaría de la Presidencia.

31 Véanse, R. Carrillo Arronte, La estrategia del desarrollo regional en México: ... loc. cit., y Rodrigo Medellín, "La dinámica del distanciamiento social en México", en M. Wionczek (Comp.), op. cit. En estos dos estudios se considera al Distrito Federal como una región y es fácil entender como al considerar otras regiones con amplias zonas rurales y compararlas prácticamente a una ciudad (la ciudad de México), el distanciamiento aumenta lógicamente. De esta manera, estos autores lo que en realidad están midiendo es el distanciamiento en el desarrollo económico entre el sector rural - que es muy importante en todas las regiones- y el urbano representado por la ciudad de México. Curiosamente los otros dos estudios, de Mendoza y Wilkie, hacen lo mismo aunque sólo comparan entidades federativas y obtienen resultados opuestos.

32 Véanse, Eliseo Mendoza, op. cit.; y J. Wilkie, op. cit.

33 Luis Unikel, Gustavo Garza y Crescencio Ruiz Chiapetto, El desarrollo urbano de México, diagnóstico e implicaciones futuras, Vols. I y II, Centro de Estudios Económicos y Demográficos de El Colegio- de México, 1974, Caps. II, VI y X (en prensa). Para efectos del análisis regional, el país se dividió en siete regiones según grupos de entidades mencionadas en el texto. 
tèriores de regiones con respecto a las más atrasadas, la Centro-norte y Centro, es cada vez mayor. Aunque no es posible juzgar la mayor o menor precisión de los resultados obtenidos en los distintos estudios, máxime que no son totalmenie comparables, parece que los del cEED están más acordes con la complejidad de la dinámica regional, tanto de la urbanización como del desarrollo económico.

En cuanto a los factores geográficos, históricos y de economía política que han generado las disparidades regionales en México y su evolución, sen̂̉alaremos algunos elementos adicionales a los planteados antes.

\section{Preocupación gubernamental}

La preocupación por el desarrollo regional en México no es reciente, pero no cabe duda que ésta ha alcanzado su máxima expresión relativa durante la presente administración. Esta preocupación surge de los crecientes trastornos sociales y problemas económicos que enfrenta el país, entre otros los que genera el desempleo y el subempleo de grandes volúmenes de población económicamente activa, los ínfimos niveles de vida de grandes masas de población rural y urbana, la polarización de intereses económicos, políticos e ideológicos, etc. En vista de que el gobierno atribuye gran parte de la culpa al modelo económico "desarrollista" aplicado hasta 1970, el cual ". . 'amenazaba' con crear un colonialismo interno, 'y esto es injusto, es explosivo y es un cuello de botella para un desarrollo sano'..."34 Por estas razones, la actual administración ha formulado "... [como un] objetivo prioritario el remediar los desequilibrios sociales, políticos y económicos, generados por el proceso mismo de crecimiento. En el caso contrario, la sociedad desatendería su función de garantizar la estabilidad social y política".35

Las dos aseveraciones anteriores, la primera de un ministro del actual gabinete proveniente de la iniciativa privada - pues durante una administración anterior fue presidente de la concAMIN- y la segunda, de un grupo selecto de economistas del sector público, son una señal de que la preocupación gubernamental por el desarrollo regional no es producto de elucubraciones. Con seguridad responde a crecientes presiones scciales y políticas, ${ }^{36}$ tanto de las entidades atrasadas y aún de las más avanzadas, incluida la zona metropolitana de la ciudad de México, por captar una mayor proporción de los recursos nacionales para satisfacer sus crecientes necesidades, así como de las que deben ejercer algunos grupos de poder urbanos que ven en la ininterrumpida concentración de población en la ciudad de México y en otras ciudades grandes, y en la

34 Véase Carlos Arriola, "El presidente Echeverría en Latinoamérica", Foro Internacional, Vol. XV, Núm. 1, El Colegio de México, 1974, p. 105.

35 Grupo de Estudio del Problema del Empleo, El problema ocupacional en México, magnitud y recomendaciones, versión preliminar para discusión, 1974, p. 3.

36 Véase Yoram Shapira, "La experiencia sinaloense y el federalismo mexicano", Foro Internacional, El Colegio de México, Vol. XV, Núm. 1, p. 72. 
manifestación abierta de sus condiciones de marginalidad, el peligro latente de que se agudicen los conflictos sociales y que estos se expresen en forma violenta.

Las razones anteriores sólo dan una idea simplista de una realidad sociopolítica mucho más compleja y difícil de conocer dada la escasa información existente sobre el sistema de toma de decisiones en México. Sin embargo, al margen de la mayor o menos validez de los motivos expuestos y que se cree han conducido al gobierno mexicano a plantear en forma más decidida y explícita las bases de una política de desarrollo regional y de descentralización industrial, consideramos de primera importancia intentar valorar lo realizado hasta el presente para poder visualizar las perspectivas futuras. Antes de intentar un análisis somero de las políticas gubernamentales de desarrollo regional en México, formuladas antes y después de 1970, es necesario examinar, aunque sea brevemente, dos temas importantes: lo que se entiende por políticas regionales $o$ de desarrollo regional y por "evaluảción" de políticas.

\section{VI. ¿QUÉ ES UNA POLÍticA REgIONAL?}

Cuando se dice que un gobierno tiene una política de desarrollo económico nacional o regional, ¿qué es lo que se entiende por ello? En América Latina, en general, se utilizan indiferentemente y a veces como sinónimos: política de desarrollo, programa y plan, ${ }^{37}$ y casi ninguno de los estudios que trata de políticas ha intentado definir los diversos términos y conceptos que el planificador, el político, y el cientista social aplican con tanta frecuencia, pero con escaso rigor.

Cuando hablamos de una política regional del gobierno ¿qué se supone que contenga? ¿qué elementos la conforman? ¿qué requisitos debe cumplir una declaración oficial para que constituya una política? Lo mismo que se menciona sobre la política regional, se hace sobre la descentralización industrial; la política educativa, agraria, hidráulica, de energéticos, carretera, fiscal, monetaria, etc. $\mathrm{O}$ sea que existen políticas globales de desarrollo económico y social, nacionales o regionales o estatales; políticas sectoriales y subsectoriales. ¿Podemos decir que todas son políticas? ¿o algunas son políticas y otras son instrumentos para llevar a cabo las políticas? A este respecto, la llamada política fiscal que forma parte de la política hacendaria, ¿no son ambas instrumentos para llevar a cabo la política de desarrollo general del país? ¿O bien, unas son políticas generales y otras son políticas subordinadas? Alguna diferenciación debe haber si es que todas lo son, o bien hay que distinguir cuáles lo son y cuáles no.

De momento sólo he intentado dar respuesta a la primera pregunta,

37 Esto se observa en varios de los estudios compilados por Jorge Hardoy y Guillermo Geisse (Comps.) en Políticas de desarrollo urbano y regional en América Latina, Buenos Aires, Argentina, Ediciones siap, 1972. 
la más general. ¿Qué es una política regional? y aún esto no creo haberlo resuelto. Por desgracia, no existen, salvo en casos excepcionales, definiciones explícitas del concepto mencionado y, por lo general, hay que hacer inferencias de las discusiones sobre el tema.

Algunos autores consideran que una "política" es la declaración oficial de una doctrina, propósito, intención o deseo, con el compromiso tácito de llevarla a la práctica. ${ }^{38}$ Otros piensan que es una acción o una serie de acciones llevadas a cabo por representantes del gobierno nacional. ${ }^{39}$ Hardoy y Moreno van aún más lejos al aseverar: "Por políticas se entienden todas las medidas emanadas del aparato del Estado y destinadas a cumplimentar la función general de dominación conforme al modelo social hegemónico." 40

Dentro de esta divergencia de opiniones llegué a la conclusión de que política regional es "... un proceso político del Estado que intenta rectificar para corregir los desequilibrios inherentes... [a] las contradicciones del sistema económico" ${ }^{41}$ y, para lo cual, se ocupa "... de los factores que gobiernan la localización de actividades económicas y población, a la luz de los requisitos tecnológicos y económicos, de las necesidades y de las aspiraciones humanas, así como de las características de las áreas en cuestión". ${ }^{42}$

Entre los atributos que considero que debe reunir una política regional están los siguientes:

a) Debe ser viable de llevarse a cabo, de lo contrario resulta ser sólo un buen deseo, una utopía que por impracticable se vuelve letra muerta o demagogia.

b) Debe contener objetivos claros y específicos. Deben ser más precisos que las metas sociales generales, tales como elevar el nivel de vida, dotar a toda la población de un alojamiento satisfactorio a sus necesidades, etc. Si los objetivos no son concretos, aunque no se expresen cuantitativamente, más que sobjetivos son declaraciones de principios que por abstractos no tieneri discusión. Una política que se plantea en términos demasiado generales también puede ser demagógica en el sentido que toda acción encaminada a cumplirla, sin importar de que tipo ni monto, la satisface.

38 Definiciones verbalmente expuestas por Donald Miller, investigador de la Universidad de Seattle.

39 T. Ecker, Capitalist Planning, the State and Regional Policy; Some Comments on Britain in the Mid- 1960's, Polythecnic of Central London, 1974 (mecanografiado).

40 Jorge Hardoy y Oscar Moreno, "Tendencias y alternativas de la reforma urbana", en Luis Unikel y Andrés Necochea (Comps.), Problemas y politicas de desarrollo urbano y regional en América Latina. F.C.E., 1975.

41 Elizabeth Lebas, Sociology of Regional Planning and Policy: Theoretical and Methodological Problems, Working Paper 14, Polythecnic of Central London, 1974 , p. 1 .

12 Commision of the European Communities, A Regional Policy for the Com. munity, Luxemburgo, 1969, p. 22. 
c) Las políticas deben permitir que las acciones del gobierno puedan ser juzgadas sobre la base de su racionalidad, por lo menos en dos formas: en primer lugar, que incluyan indicaciones operativas sobre la forma factible de lograr fines positivos (o evitar resultados negativos) $y$, en segundo lugar, proporcionando marcos de referencia para la realización de las actividades y programas administrativos de aplicación diaria.

d) Aunque lo importante de una política es su contenido, sus alcances y logros, no menos importante es el aspecto formal - no por la presentación por cuanto a que el documento debe ser oficial, aunque no sea necesariamente una ley, acuerdo o decreto. De hecho las políticas de desarrollo regional o urbano en países como la Gran Bretaña no tienen carácter legal, sino peso político. ${ }^{43}$ Sin embargo, debe incluirse en un documento de gobierno, el cual debe contener la declaración de la intención fundamentada por una serie de considerandos que expliquen el porqué se formula la política, qué alcances tendrá, antecedentes de políticas o acciones aplicadas en resolver problemas regionales; los objetivos; las acciones que tomará el gobierno para cumplir los objetivos, etcétera. ${ }^{44}$

e) Debe tener alcance nacional, o sea que los objetivos e instrumentos deben referirse a todas y cada una de las regiones del país o a todas las regiones de ciertas características, como las más pobres, las decadentes, etc. En uno u otro caso, la política regional debe formar parte integral de la política nacional de desarrollo socioeconómico y debe dar a conocer por qué y en qué forma pretende contribuir al desarrollo del país.

\section{La "Evaluación" de políticas de desarRollo Regional}

Un estudio que "evalúa" la política regional británica durante los años sesenta recomienda, para hacerlo, examinar la relación entre el Estado y el sistema económico. Para ello identifica dos grandes enfoques: el de índole positivista - ateórico- aceptado por estudiosos de diversas tendencias políticas, inclusive algunos marxistas; y otro que trata de analizar en una perspectiva teórica el desarrollo de las relaciones capitalistas y el papel del Estado. El primero busca explicar la creciente intervención estatal en términos de hechos directamente observables y le atribuye al Estado una función exclusivamente administradora y coordinadora. El segundo enfoque parte de la premisa de que el Estado “... puede considerarse que opera a favor de los intereses de un grupo específico; de la burguesía". ${ }^{45}$ Asimismo, supone que el sector privado demanda la intervención estatal debido a razones esencialmente económicas, mientras

43 Brian McLoughlin, Control of Urban Planning, Londres, Faber \& Faber, 1973, pp. 161 y 162.

44 Esta sugerencia se desprende del análisis de algunas de las políticas de la Gran Bretaña expresadas en los documentos denominados White Papers.

45 T. Ecker, op. cit., p. 2. 
que las funciones políticas y administrativas del Estado quedan relegadas a un segundo plano, no obstante su importancia.

Este último enfoque exige información que no se tiene a la mano, sino que hay que leerla entre líneas en la prensa y en los estudios y documentos gubernamentales. Esta es una razón significativa por la cual se da preferencia al primer enfoque.

La evaluación de políticas de desarrollo regional, y en general de todo tipo de políticas gubernamentales es una labor bastante desarrollada en los países ricos, en particular en aquellos como la Gran Bretaña que han acumulado cuarenta años de experiencia en materia regional. De hecho, la formulación de una política (White Paper) es consecuencia de la "evaluación" de su antecesora.

Los países de América Latina muestran a este respecto un marcado contraste y aunque durante los últimos años se han multiplicado las "evaluaciones" de los programas regionales, tanto de América Latina como a escala nacional, no es exagerado decir que los nuevos programas regionales adolecen de deficiencias, entre otras razones porque se formulan sin tomar debida cuenta de las escasas "evaluaciones" existentes, porque no se dispone de exámenes recientes o porque los estudios no reúnen las condiciones necesarias para ser tomadas en cuenta. Sin embargo, esto también es producto de que los gobiernos de América Latina no incluyen entre sus actividades regulares la "evaluación" periódica y públicamente expuesta de sus realizaciones, ya sea que esté elaborada por funcionarios del propio sector público, o por académicos y técnicos externos comisionados por el gobierno.

\section{ViII. La "evaluación" De políticas regionales en México}

En el caso de México las "evaluaciones" realizadas han seguido un enfoque de naturaleza positivista, en el sentido de que han considerado en forma implícita la función del Estado como administradora y reguladora de la actividad pública y complementaria de la del sector privado; sin embargo, aun sin contar con un marco teórico de la función del Estado, llega a la conclusión de que el segundo enfoque de análisis plantea como premisa que "todas estas medidas [las del gobierno] han favorecido a los empresarios nacionales y extranjeros, a los agricultores situados en el sector comercializado y a los habitantes con ocupación productiva de los principales centros urbanos del país". ${ }^{43}$

46 Dirección General de Programación y Descentralización Administrativa, Bases para la regionalización de la administración fiscal federal, Secretaría de Hacienda y Crédito Público, 1973, p. 14. A conclusiones más radicales llegan autores como Sergio de la Peña, "Requisitos de la planificación: un enfoque histórico, en M. Wionczek (Comp.), op. cit., y Arturo Guillén, Planificación económica a la mexicana, Editorial Nuestro Tiempo, 1971; David Barkin, "¿Quiénes son los beneficiarios del desarrollo regional?", op. cit. 
En México las "evaluaciones oficiales" de lo realizado por el sector público son, en general, salvo excepciones recientes, de índole descriptiva y con fines informativos. Además de los informes presidenciales, los programas de gobierno se presentan al examen público a través de exposiciones gráficas o de las publicaciones periódicas de sus distintos ministerios. En esta labor, el sector público federal gasta grandes sumas de dinero que pudieran rendir mejores frutos para la propia actividad de gobierno, si una parte de tales recursos se destinaran a la "evaluación" objetiva e imparcial de la labor gubernamental en el cumplimiento de los objetivos formulados antes y durante su período constitucional. Asimismo, durante la presente administración, se ha utilizado con frecuencia lo que se denomina "autocrítica", o sea la de que un alto funcionario de gobierno expresa en relación a las deficiencias observadas dentro de su propio departamento o del sector público en general. Sin embargo, este tipo de críticas son demasiado generales y se duda de los propósitos reales de tal actitud y los motivos subyacentes que llevan a la mencionada "autocrítica". No obstante, no deben pasar inadvertidos, pues dan idea de algunas fallas del sector público y del privado, de los conflictos de intereses entre estos dos sectores y dentro del primero de ellos. En esta tarea, y en general en la de informar y analizar la labor del gobierno - a pesar de las limitaciones impuestas por el sistema sociopolítico-, un reducido sector de la prensa en México realiza una labor importante. Por desgracia, salvo excepciones, ni la prensa ni la televisión cuentan con el personal con preparación adecuada para llevar a cabo una labor de "evaluación" socioeconómica y política. Esta tarea, por lo menos la que se conoce en forma escrita, la han realizado algunos cientistas sociales quienes a través de publicaciones académicas gozan de menores limitaciones para expresar su opinión y pueden, por lo tanto, emitir juicios más severos, o bien disponer de mayor tiempo para fundamentar más amplia y detalladamente su evaluación. ${ }^{47}$ Estos estudios académicos o elaborados por académicos por comisión gubernamental, son las que a la postre han conservado su valor a más largo plazo y han servido principalmente a los propios académicos para mantener la continuidad necesaria en la "evaluación" de los programas y planes de gobierno, pero se cree que en alguna medida han influido en la toma de decisiones del gobierno. Por ejemplo, aunque se desconoce la magnitud del impacto, pienso que estudios como los de Romero Kolbeck y Urquidi, Yates, y Barkin y King ${ }^{48}$ han influido en la toma de decisiones del gobierno en

47 Esto de ninguna manera niega la existencia de una prensa de protesta política en México. Aunque limitada, la hay. Es más, un grupo de relativa importancia de académicos participan significativamente en esta tarea crítica a través de la prensa. Sin embargo, en el texto me refiero a las investigaciones sobre las políticas gubernamentales y que los británicos denominan policy oriented.

48 Gustavo Romero Kolbeck y Víctor L. Urquidi, La exención fiscal en el Distrito Federal como instrumento de atracción de industrias, Departamento del Distrito Federal, 1952; P. L. Yates, op. cit.; D. Barkin y T. King, op. cit. 
cuanto a la derogación de la ley de exención fiscal en el Distrito Federal en 1954, en el primer caso; y en lo que respecta a las medidas que el gobierno ha tomado a partir de 1970, en materia de descentralización industrial y desarrollo regional, en los otros dos casos. Sin embargo, debe admitirse también que esta influencia ha sido demasiado lenta, por lo menos en lo que respecta al estudio de Yates. Durante las administraciones de López Mateos y Díaz Ordaz, se puede decir que este estudio no tuvo impacto alguno, o bien, no se expresó en medidas específicas del sector público que fueran indicio de un cambio de actitud hacia el desarrollo regional. ${ }^{49}$ Sin embargo, se presume que el estudio de Yates estimuló el interés de varios académicos por tratar de explicar la naturaleza de los problemas regionales en México, así como de evaluar las realizaciones en materia de planeación regional.

Otro ejemplo más reciente y de influencia más notable en la política industrial, del estado de Sinaloa, es un análisis elaborado por el propio Yates para el entonces gobernador de esa entidad federativa (1967). El informe privado no difundido de Yates, hecho por comisión del gobernador, contiene “... una 'evaluación' exacta de las barreras que bloquean el camino de Sinaloa hacia el desarrollo industrial". ${ }^{50}$

\section{Intentos de planeación eConómica en México hasta 1970}

De acuerdo con las consideraciones hechas sobre política regional, México no ha tenido antes de 1970 , y no tiene todavía una política nacional de desarrollo socioeconómico regional, aunque está en camino de formularse la primera.

Los intentos de planeación económica en México han sido principalmente sectoriales y a escala nacional. La asignación de recursos se ha hecho, tanto en sectores llamados básicos, como comunicaciones, irrigación, industria, agricultura, etc. como en sectores de llamado beneficio social, tales como educación, vivienda, salud pública, etc. Esto implica que con excepción hecha de los programas o proyectos regionales como el de cuencas hidrológicas o el programa nacional fronterizo, el gobierno no se ha interesado, y seguramente no le ha convenido tener una estrategia territorial de distribución del gasto público aun cuando los programas sectoriales han tenido efectos espaciales importantes.

49 Fuera de los estudios regionales elaborados por la Dirección de Planificación de la Secretaría de la Presidencia y que nunca llegaron a los gobiernos de los estados que fueron motivo de estudio (los de la Península de Yucatán, Oaxaca y de otros estados), casi no se realizaron estudios, ni planes regionales. No extraña no encontrar casi referencia alguna a planeación regional en los cinco primeros informes presidenciales de López Mateos. Aunque durante Díaz Ordaz se hicieron algunos intentos débiles en materia de desarrollo rural e industrialización estatal, no suman mayor cosa. Véanse 5 Informes de Gobierno, México, 1964; y Secretaría de la Presidencia, La planeación en México, 1968.

50 Y. Shapira, op. cit., p. 75. 
Creemos que una política de esta índole implicaria para el gobierno un "costo político" - no por los compromisos y presiones a que estaría sujeto, tanto de aquellas entidades, regiones o municipios que recibieran un trato especial en materia de inversiones, como de las restantes-, costo que no ha estado dispuesto a pagar. Sin embargo, antes de 1970, no parece que los gobiernos se hayan preocupado por esto; más bien, parecían convencidos, en particular desde Ávila Camacho a Díaz Ordaz (1940-1970) de la bondad de la estrategia "desarrollista" para obtener una tasa de crecimiento del producto interno bruto elevada y sostenida a largo plazo, a través de la concentración de recursos de capital para estimular el ahorro privado y las inversiones internas, utilizando la inversión pública para impulsar la formación de capital privado. ${ }^{51}$ El modelo aplicado supone que una vez que el "pastel" (bienes y servicios producidos) de la riqueza nacional fuese mayor, más fácil sería repartirlo en forma equitativa, o dicho en otros términos, implica darle prioridad a la "eficiencia" económica con respecto a la equidad o justicia social.

Las deficiencias técnicas y administrativas de los intentos de planeación económica sectorial, su escasa difusión, la falta de objetivos formulados con claridad y el temor al compromiso político de establecer metas de escaso alcance, los hace acreedores a distintos calificativos: parciales, informales, incompletos, utópicos, triviales y secretos.$^{\widetilde{\sigma}}$ De hecho, la planeación económica nacional tal como se plantea en los dos planes sexenales, en el Plan de Acción Inmediata 1962-1964 y en el Plan de Desarrollo Económico y Social 1966-1970, no ha tenido más resultados que los que de todos modos hubiera tenido mediante la aplicación de la serie de instrumentos de desarrollo sectorial vigentes, o aún más, como consecuencia de los procesos que espontáneamente hubieran generado las fuerzas económico-sociales que han participado en el desarrollo nacional.

Los intentos de planeación no han constituido un proceso continuo del sector público. Tuvieron que pasar dieciocho años después de los dos planes sexenales (1934-1946), para que, de manera circunstancial y debido a factores externos, se intentara de nueva cuenta un plan a escala nacional: el Plan de Acción Inmediata 1962-1964. Su formulación obedeció a la necesidad del país de obtener crédito externo, para lo cual tenía que cumplir con los requisitos establecidos por la Alianza para el Progreso. Durante las administraciones de López Mateos y Díaz Ordaz

51 Antonio Ortiz Mena, "Desarrollo estabilizador; una década de la estrategia económica en México", Mercado de valores, Núm. 44, noviembre de 1969, citado por D. Barkin, “¿Quiénes son los beneficiarios del desarrollo regional?", op. cit. D. 156.

52 Véanse, A. Guillén, op. cit., y M. Wionczek, Antecedentes de la planeación en México; bases para la planeación económica y social de México, Siglo XXI, 1966; Juan Proel, "Los intentos de planificación económica en México", Comercio Exterior, Vol. XXIII, Núm. 1, 1973; D. Barkin y T. King, op .cit.; A. Lavell. Development Planning in Mexico (en prensa); Guy Benveniste, Bureaucracy and National Planning, A Sociological Case Study in Mexico, Nueva York, Praeger Publishers, 1970; R. Shafer, Mutual Adjustment Planning, Syracuse, 1966. 
(1958-1970), la planeación económica perdió progresivamente el impulso momentáneo que tuvo durante el régimen del primero. No extraña que el pobre papel que jugó la planeación en este sexenio haya contribuido - ante las grandes expectativas que había despertado- a que el régimen de Díaz Ordaz sea calificado como uno de los más apáticos en cuanto a la planeación y el más conservador y sigiloso. El Plan de Desarrollo Económico y Social 1966-1970 que se formuló se conoce como el plan "secreto", pues nunca se hizo público, entre otras razones para evitar. críticas. La frustación causada por la ineficacia de la planeación formulada durante estos doce años fue, entre otros motivos, el que ésta actividad gubernamental se desprestigiara aún más de lo que ya estaba y que, por lo mismo, a fines del régimen de Díaz Ordaz nadie hablara de ella y que los planes y múltiples estudios sectoriales, regionales y estatales se archivaran una vez más. Con seguridad, la desilusión acumulada respecto a la eficacia de la planeación, y su pobre imagen política, fueron razones de peso por las cuales desapareció la Dirección de Planeación de la Secretaría de la Presidencia y en su lugar se creara la Dirección de Estudios Económicos.

\section{ACcIONES destinadAS A CORREgIR los DESEQUilibrios REGIONALES Y LA MACROCEFALIA}

Al lado de este débil marco de planeación de la economía nacional y de ciertos intentos por aumentar la racionalidad en la distribución del gasto público (Comisión Nacional de Inversiones, Direcciones del Gasto Público y de Inversiones de la Secretaría de la Presidencia), el gobierno ha puesto en práctica unas cuantas medidas diseñadas explícitamente como parte de un plan de desarrollo interregional o de una región en particular, con el objetivo específico de intentar la descentralización industrial, el fomento de zonas atrasadas y, en general, el desarrollo regional.

A la fecha, el programa de desarrollo regional más amplio ha sido el de las Comisiones Hidrológicas que fue iniciado por Miguel Alemán en 1947 al crear las Comisiones del Papaloapan y del Tepalcatepec. Aun cuando el programa no expresaba con claridad sus objetivos en cuanto a descentralizar actividades industriales o población, sí planteaba aliviar "... el congestionamiento de nuestra Mesa Central, cuyas extenuadas tierras habrán de consagrarse a cultivos que la política colonial les negó..." 5 st

Según la evaluación detallada hecha por Barkin y King sobre este programa, "...éste ha contribuido sin duda al desarrollo nacional y al

53 G. Benveniste, op. cit., p. 86.

54 Discurso del presidente Ávila Camacho de julio de 1941, citado por Stanford Mosk, Industrial Revolution in Mexico, Berkeley, University of California Press, 1954, p. 220. 
desarrollo agrícola e hidrológico regionales; sin embargo, los proyectos han logrado poco ... como una estrategia para lograr la descentralización económica o para reducir la corriente de emigrantes hacia las zonas urbanas..." 55 Asimismo, y no obstante que las leyes que crearon las "Comisiones" les otorgan amplias facultades para dictar las medidas y disposiciones en materia industrial, este propósito fue explícitamente excluido en la mayoría de los programas, excepto para las industrias de procesamiento agrícola directo. ${ }^{56}$

Por razones aún más poderosas, pues sólo tenía funciones de estudio, la Comisión Hidrológica de la Cuenca del Valle de México, tampoco alteró en grado alguno la tendencia de crecimiento de la zona metropolitana de la Ciudad de México (ZMCM). En sus 21 años (1951-1972) de existencia éste ha sido el único organismo gubernamental que incluía representantes de las entidades federativas que forman parte de la zMcM, lo cual constituye una experiencia importante, aunque nunca llegó realmente a coordinarlas. También fue la única de la comisiones hidrológicas que se preocupó por formular un plan hidráulico que incluia objetivos explícitos de distribución de población y actividades económicas y, principalmente, que proponía la idea y la forma de frenar el crecimiento de Ia ZMCM. $^{57}$ Lo utópico de las medidas propuestas para lograr tal propósito, al plantearse fuera del contexto socio-político, hizo que el plan nunca se aceptara oficialmente, ni por la propia Secretaría de Recursos Hidráulicos.

Dentro del programa de industrialización, el Fondo de Garantía a la Pequeña y a la Mediana Industria ha sido el único organismo crediticio que, antes de 1970, ha propuesto explícitamente darle preferencia a las empresas localizadas fuera de las áreas de concentración industrial, específicamente del Distrito Federal y Monterrey. Después de 17 años de vigencia (1953-1970), el fondo ha logrado aumentar ligeramente la participación de las entidades en el crédito industrial y reducir la del Distrito Federal. Sin embargo, el Estado de México - seguramente la parte incluida en la $\mathrm{ZMCM}$ - ha visto aumentar su participación en el Fondo: del $10 \%$ que recibió de 1953 a 1961 al $20 \%$ en $1970,{ }^{58}$ pues no estaba catalogada como área de concentración industrial. Por lo tanto, en contraste con el efecto descentralizador que esta medida ha tenido -aunque

55 D. Barkin, ¿"Quiénes son los beneficiarios...?" op. cit., p. 183.

56 W. Stohr, op. cit., p. 183.

57 Ing. José Vicente Orozco, "Plan hidráulico para el Valle de México", Instituto Mexicano de Recursos Renovables, Mesas redondas sobre problemas del Valle de México, México, 1963, pp. 51-52. Para mayores detalles, véase La Comisión Hidrológica de la Cuenca del Valle de México, su origen, finalidad y resultados, hasta 1963, Comisión Hidrológica de la Cuenca del Valle de México, Secretaría de Recursos Hidráulicos, febrero de 1964. Para una crítica al mencionado plan hidráulico, véase Luis Unikel, "Consideraciones sobre los centros urbanoindustriales que propone el Plan Hidráulico para la cuenca del Valle de México", septiembre de 1965, documento mecanografiado.

58 A. Lavell, "Regional..." op. cit., cuadro 7. 
débil- también ha generado mayor concentración industrial en la zMCM, produciendo efectos contradictorios respecto a los objetivos que pretendía alcanzar en cuanto a descentralización industrial.

Algo semejante se puede atribuir a la derogación en 1954 de la Ley de Exención Fiscal para Industrias en el Distrito Federal, pues no obstante las buenas intenciones del gobierno de eliminar el desperdicio de recursos que se estaban otorgando inútilmente a los industriales, vía exenciones, éstos de todos modos se hubieran establecido en el Distrito Federal.

El resultado de esta aparente pretensión del gobierno de concederle mayores ventajas competitivas a la provincia con respecto al Distrito Federal fue contraproducente: ni se promovió la industrialización estatal, porque todas las entidades ofrecen casi las mismas exenciones - lo cual neutraliza su efecto- y éstas de todos modos son de poca monta; ni se evitó que se incrementara la macrocefalia.

El gobierno no captó - por ignorancia o por las dificultades inherentes a los enormes intereses creados - el hecho de que la zona metropolitana es una unidad ubicada dentro de dos entidades federativas contiguas y que la aplicación unilateral de instrumentos del sector público en materia industrial, como abastecimiento de agua potable, drenaje, incentivos fiscales, etc. entre el Distrito Federal y el Estado de México, contribuyen a la creciente metropolización de la capital y al incremento de la macrocefalia.

Los llamados parques y ciudades industriales son instrumentos que han venido adquiriendo mayor importancia dentro del conjunto de medidas que el gobierno ha dictado para descentralizar la industria nacional hacia la provincia.

La construcción de estos parques y ciudades -iniciada en 1953 con Ciudad Sahagún - se ha venido realizando sin estrategia general alguna tanto por los gobiernos federal y estatal como por la iniciativa privada. La ubicación de los 22 parques y ciudades industriales que se construyeron de 1953 a 1970 - de los cuales 14 son de propiedad privada- ha estado gobernada por consideraciones de mercado más que por intenciones de descentralización. De esta forma, se ha permitido que un porciento elevado de los parques se hayan localizado cerca de o en la zMCM, contribuyendo a la continua metropolización y macrocefalia de la ciudad de México y al fortalecimiento del subsistema de ciudades alrededor de ella. ${ }^{59}$

Por último, el Programa Nacional Fronterizo es otro de los tantos programas gubernamentales aislados que por motivos de estrategia sociopolítica internacional, más que de desarrollo regional, han tenido como efecto una cierta descentralización de la inversión pública y privada.

59 Véase G. Garza, "Towards a National Strategy of Industrial Estates in Mexico", Wolfson College, Cambridge University, Inglaterra, 1973; y el Fideicomiso de Conjuntos, Parques y Ciudades Industriales, Guia de Parques y Ciudades Industriales, en México, Nacional Financiera, 1972. 
De 1959 a 1965 el Programa Nacional Fronterizo, con la colaboración de las Juntas Federales de Mejoras Materiales (ambas bajo el control de la Secretaría del Patrimonio Nacional) se dedicó, principalmente, y con escaso éxito, a cambiar la apariencia física de las principales ciudades fronterizas, así como a mejorar sus servicios municipales. Durante el período 1965-1972 se dio mayor atención a la promoción industrial, a fomentar la afluencia de los productos nacionales al mercado fronterizo y a promover la creación de nuevas fuentes de ocupación. Con esta idea fue creado en 1965 el "Programa para el aprovechamiento de la mano de obra sobrante a lo largo de la frontera Norte con los Estados Unidos".

El programa ofrece diversos e importantes incentivos económicos para la localización de industrias maquiladoras y ha conseguido el establecimiento de cerca de 500 plantas y la creación de más de 80000 empleos, lo cual ha conseguido aliviar un poco el desempleo y subempleo crónicos que se padece en la frontera Norte, dada la constante y masiva inmigración que de 1940 a 1970 se ha experimentado de regiones del país en peor situación económica. A pesar del éxito de este programa gubernamental, no puede pasar inadvertido que simultáneamente se ha incrementado la dependencia de México con respecto a los Estados Unidos, por cuanto que la gran mayoría de la inversión de capital (terrenos, edificios y maquinaria) es norteamericana. Asimismo, la existencia y expansión del programa depende de los ciclos económicos en los Estados Unidos y en el mercado mundial, ya que la producción de bienes producidos en la frontera por la industria maquiladora se destina exclusivamente a ese país, ya sea para el consumo interno o para ser exportado.

En suma, se puede decir que hasta 1970 México no contó con una política de desarrollo regional ni con planes de desarrollo económico nacional que verdaderamente intentaran una redistribución personal y territorial del ingreso. El único plan que contiene entre sus objetivos uno tendiente a atenuar y corregir desequilibrios regionales (el Plan de Desarrollo Económico y Social 1966-1970) no hizo casi nada para lograrlo.

Los contados programas, proyectos y medidas administrativas que se crearon con el propósito explícito de alcanzar cierta descentralización del gasto público federal tuvieron escaso efecto, si algo se logró; entre otras razones, porque respondieron a necesidades de economía política más que al deseo de lograr una redistribución territorial y personal del ingreso. Por el mismo motivo, los objetivos nunca fueron planteados con claridad, los instrumentos creados fueron muy débiles para contrarrestar los intereses del sector privado y aún dentro del público para reducir las desigualdades regionales. Así, se puede explicar también por qué, en ocasiones, la aplicación de medidas tendientes en principio al fomento regional haya producido efectos contrarios a lo deseado.

Antes de pasar al período 1970-1975, queremos añadir un comentario más. No obstante que se cuenta ya con bastantes estudios de "evaluación" de la planeación económica nacional y regional en México, pienso 
que se debe profundizar aún más en materia de economía política, en cuanto a la función que el Estado ha desempeñado en el desarrollo económico nacional y, en particular, en el regional, ${ }^{60}$ así como en el urbano. Sólo así se comprenderá la verdadera dinámica de las fuerzas sociales del desarrollo económico y político del país. En la medida en que conozcamos quienes son los actores participantes del desarrollo, los roles que han jugado en el mismo, las razones e intereses que motivan su actitud y acción, podremos establecer con claridad las causas de los actuales desequilibrios y de las barreras para eliminarlos o reducirlos. ${ }^{61}$ Este tipo de análisis permitiría tratar de responder a una serie de preguntas para explicar por qué en México nunca se ha pretendido someter la iniciativa privada a los lineamientos de un plan indicativo, y por qué ni siquiera los organismos del sector público se han ajustado obligatoriamente a metas definidas por una institución planificadora, como la Secretaría de la Presidencia. ${ }^{62}$

\section{LA estrategia de desarrollo Regional, 1970-1975}

Desde la campaña presidencial se notó la intención del presidente Echeverría de prestar mayor atención que los gobiernos anteriores a las desigualdades regionales y a la macrocefalia urbana ${ }^{63} \mathrm{En}$ su primer discurso oficial plantea la tesis central de la estrategia que pretende seguir, al expresar: "No es cierto que exista un dilema inevitable entre la expansión económica y la redistribución del ingreso. Quienes pregonan que primero debemos crecer para luego repartir, se equivocan o mienten por intereses." "Para el ejecutivo Federal, gobernar será distribuir equitativamente el fruto de redoblados esfuerzos; hacer que las regiones y los grupos más afortunados contribuyan al desenvolvimiento de los más atrasados..." "84 "Evitaremos que los beneficios ... sigan concentrándose

60 El magnífico ensayo de Y. Shapira sobre la economía política del desarrollo de Sinaloa, es un ejemplo del tipo de estudios que se recomienda elaborar para todas y cada una de las entidades federativas, así como de grupos de entidades que forman regiones. Véase Y. Shapira, loc. cit

61 Véanse, Ricardo Pontual, "Racionalidad formal vs. racionalidad sustancial en el proceso de planificación del desarrollo urbano", en Revista Interamericana de Planificación, Vol. VII, Núm. 26, junio de 1973, y Rolando Ramírez, Planning in a Social Vacuum: National Development and Urbanization of Chile, ponencia presentada al seminario del Royal Town Planning Institute, Exeter, Inglaterra, septiembre de 1974 .

62 J. Proel, op. cit., p. 665.

63 Esta se expresa a través de las numerosas ponencias que técnicos, planificadores y académicos presentaron en las Reuniones Nacionales sobre industrialización y desarrollo regional, respectivamente en Naucalpan, Estado de México y la ciudad de Aguascalientes durante 1970, organizadas por el IEPES.

64 Luis Echeverría, "Discurso de toma de posesión", $1^{\circ}$ de diciembre de 1970 , en Jorge Eduardo Navarrete (Comp.), La politica económica del nuevo gobierno, Banco Nacional de Comercio Exterior, 1971, p. 180. 
en unas cuantas zonas. Es urgente remodelar el espacio económico: crear polos de crecimiento..." ${ }^{65}$ En principio parece que la idea generadora de la iniciativa es ia creciente preocupación por parte del gobierno y aún de algunos sectores fuera de él, de que la persistencia de los desequilibrios sectoriales y geográficos ponen en peligro la posibilidad misma de que el proceso de crecimiento económico pueda continuar.

¿Cuáles pueden haber sido los motivos que condujeron a este cambio de estrategia? La lista puede ser larga y algunos de ellos posiblemente indeterminables. Sin embargo, además de algunos factores que parecen tener validez social, no queda otra cosa que plantearse cuestiones lógicas que estudios posteriores puedan contestar o eliminar por irrelevantes.

Entre los primeros está la presión ejercida por las entidades federativas de la periferia - según parece no las más pobres y rezagadas, sino de aquellas como Sinaloa, que está en la región cuyo desarrollo económico se ha acercado más rápidamente al del Valle de México- por revisar la actual relación federal-estatal y demandar una mayor autonomía económica. ${ }^{66}$ Shapira, en su análisis, llega al punto de atribuir el enfoque dinámico de la presente administración, en buena medida, a la influencia ejercida por las tácticas de presión aplicadas por algunas entidades durante los años sesenta, así como al descontento acumulado a ese nivel. ${ }^{67}$ Este malestar parece deberse a la creciente percepción que en algunas entidades se ha alcanzado del pobre papel que tradicionalmente han desempeñado sus representantes, de solicitantes-intercesores ante el gobierno federal, y de la necesidad de emplear continuamente tácticas suplicantes ante la Federación para conseguir aumentos en sus asignaciones presupuestales ${ }^{68} \mathrm{y}$ en la realización de obras públicas. Dicho en otros términos, algunas entidades federativas en México tienen una idea más clara de las limitaciones que le han sido impuestas por el sistema político económico centralista de México y ha intentado inducir “... cambios estructurales y fortalecer la posición colectiva de todos, o por lo menos de un grupo regional de estados mexicanos dentro del sistema federal". ${ }^{69}$

¿Será el cambio de estrategia gubernamental mediante una política regional de inversiones, aunque parezca paradójico, una medida del Estado para evitar el fortalecimiento de fuerzas políticas centrífugas y un regionalismo que pueda en un momento dado poner en peligro la continuidad del desarrollo económico con estabilidad social de los últimos cuarenta años? ${ }^{70}$ ¿Será una estrategia para que el Estado pueda aumentar su cohesión interna y su capacidad para enfrentarse a las presiones

65 Ibid., p. 184.

66 Jorge E. Navarrete, op. cit., p. 17.

67 Y. Shapira, loc. cit., pp. 101 y 102.

68 Ibid., p. 72 .

69 Ibid., pp. 102-103.

70 Rafael Segovia, "La reforma política: el ejecutivo federal, el PRI y las elecciones de 1973", Centro de Estudios Internacionales, La vida politica en México 1970-1973, El Colegio de México, 1974, p. 58. 
populares directas y potenciales, a las de los "feudos" locales y regionales que le impiden la orientación del desarrollo social en la dirección del beneficio nacional y mayoritario ${ }^{i 1}$ ¿Será la nueva estrategia de crecimiento económico con redistribución regional y personal, la “. . única salida al dramático problema nacional de falta de empleo y poder adquisitivo popular"? ${ }^{72}$

Al margen de los motivos que haya tenido el gobierno del presidente Echeverría para formular la nueva estrategia del gobierno federal, éste ha puesto en vigor un elevado número de medidas sectoriales en materia industrial, agropecuaria, hidráulica, así como disposiciones administrativas, fiscales y de otra índole, con objeto de intentar la descentralización industrial del Valle de México y el desarrollo regional. El análisis de tales medidas resulta de momento difícil de realizar y posiblemente hasta prematuro, en vista de la breve vigencia de casi todas ellas, pero principalmente por la carencia de información y también porque el efecto de estas medidas, teóricamente correctoras de las desigualdades regionales y de la macrocefalia, sólo son visibles a largo plazo. ${ }^{73}$ Por estas razones sólo se mencionan los instrumentos más importantes, se examinan brevemente algunos de ellos y se plantea una serie de preguntas que considero importantes respecto a lo que intenta ser la primera política nacional de desarrollo regional en México. Las medidas vigentes pueden clasificarse, grosso modo, en dos grandes categorías: a) de acción directa o promocionales $y ;$ b) de coordinación. Las primeras fueron promulgadas, más o menos, durante los tres primeros años del presente gobierno, o sea de 1970 a 1973 (diciembre) y las segundas, particularmente, de fines de 1973 al presente.

En el primer grupo predominan medidas que tratan de influir directamente en la localización de las actividades industriales, comerciales y agropecuarias $\mathrm{y}$, por lo tanto de la población, de modo que se localicen fuera del Valle de México o en determinadas regiones atrasadas del país.

En el segundo grupo predominan los instrumentos orientados a coordinar la acción de todo tipo de medidas, ya sea que tengan por objeto, explícito o no, la descentralización industrial o el desarrollo regional, y que pretendan alcanzar metas más generales de desarrollo económico y social integral, más equilibrado y con un ingreso distribuido de manera más equitativa.

$\mathrm{Al}$ primer grupo corresponden las ampliaciones y nuevas atribuciones de fomento y promoción industrial de Nacional Financiera tales como la creación de: fondos de estudios de preinversión industrial en cada estado, el Fondo Nacional de Fomento Industrial y el Fideicomiso para

71 Manuel Camacho, "El poder: Estado o feudos políticos", en Centro de Estudios Internacionales, op. cit., pp. 89-98.

72 R. Carrillo Arronte, op. cit., p. 441.

$73 \mathrm{La}$ experiencia de países como la Gran Bretaña, Francia e Italia asi lo prueba. Es más, en casos como el de Italia y Francia, después de veinticinco años de esfuerzos considerables todavía no se observan los efectos. 
la promoción de conjuntos, parques y ciudades industriales y centros comerciales, y de oficinas sucursales de Nacional Financiera en la provincia, Importante también ha sido el aumento sustancial que se ha hecho de los recursos financieros del Fondo de Garantía y Fomento a la Industria Mediana y Pequeña y su aplicación diferencial de acuerdo a las tres zonas en que se ha dividido al país según decreto de junio de 1972.

La mayoría de estos instrumentos caen bajo la responsabilidad de Nacional Financiera, excepto en el caso del Fideicomiso de conjuntos, parques y ciudades industriales, que comparte con la Secretaría de Obras Públicas. Esta última, a través de la Comisión de Desarrollo Urbano del país (CODURPA) ha seleccionado la ubicación de los proyectos, los ha diseñado y los ha construido. Esta tarea está basada en la identificación y fortalecimiento de un número exageradamente alto de "polos de crecimiento" clasificados en: submetrópolis desconcentradoras de las tres principales ciudades del país, catorce metrópolis regionales o de equilibrio, treinta metrópolis intermedias, doce centros urbanos y setenta y cuatro subcentros urbanos. ${ }^{74}$

Por otro lado, la Secretaría de Industria y Comercio tiene bajo su responsabilidad la aplicación diferenciada de una serie de estímulos fiscales, crediticios y de asesoría técnica, para el desarrollo industrial, según las tres zonas en que se ha dividido el país con base en su grado de concentración industrial. Este ministerio, a partir de 1972, cuando dejó de existir el Programa Nacional Fronterizo, también coordina un amplio programa de desarrollo económico para la frontera norte, con el fin principal de generar empleo.

A nivel de recomendación, el Grupo de Estudio del Problema del Empleo (GEPE), formado por instrucciones de la presidencia de la República, propone en materia de empleo urbano una serie de medidas tendientes a favorecer el crecimiento más lento de las tres grandes metrópolis, desalentando la migración hacia ellas. Para ello aconseja " ... establecer un sistema de precios de los bienes y servicios abastecidos por el estado (agua, energía eléctrica y transporte) de modo tal que represente el verdadero costo social de los mismos". ${ }^{75}$ También propone fomentar el de aquellas ciudades entre 50000 y 500000 habitantes que tengan condiciones propicias para servir como polos de crecimiento y ciudades de contención.

Por su lado, la Secretaría de Recursos Hidráulicos elabora desde hace un par de años un Plan Nacional Hidráulico que ha estimado las necesidades, disponibilidades y obras requeridas para el abastecimiento de agua según distintos usos, y de acuerdo con 13 regiones en que ha dividido al país.

Con objeto de promover el arraigo de la población rural en el campo y en las localidades pequeñas, la Dirección de Inversión Pública de la

74 Secretaría de Obras Públicas, Obras públicas, mayo de 1973.

i5 Grupo de Estudio del Empleo (GEPE), op. cit., p. 359. 
Secretaría de la Presidencia realiza un programa Integral de Desarrollo Rural (PIDER). A este programa pertenece la Comisión Nacional de las Zonas Áridas, la primera de las que se crearon para la promoción del desarrollo de regiones específicas y a la cual siguieron otras como la Comisión Coordinadora para el Desarrollo Integral del Istmo de Tehuantepec.

De 1971 a 1973, se crearon los Comités Promotores del Desarrollo Socioeconómico de los estados de Yucatán, Oaxaca y Chiapas, con objeto de impulsar el desarrollo de estados particularmente marginados.

Dentro de las realizaciones importantes de este primer período está la regionalización y descentralización administrativa con fines fiscales, que intenta delegar autoridad y funciones, en coordinación con las autoridades locales. Para instrumentar la citada descentralización se subdividió al país en nueve regiones (grupos de dos o más entidades adyacentes) ${ }^{76}$

Por último, no debe pasar inadvertido el segundo intento fallido de la Secretaría de la Presidencia de crear una Comisión del Área Metropolitana del Valle de México. La primera comisión funcionó en esta Secretaría durante la parte final del régimen anterior, para recopilar y llevar a cabo estudios sobre la ZMCM y para intentar la coordinación técnica entre el Distrito Federal, el estado de México y el gobierno federal. Su primer objetivo se cumplió parcialmente, pero fracasó en su tarea coordinadora. Seguramente que intereses socio-políticos en el Distrito Federal o el estado de México y posibles desacuerdos de éstas con la Federación, se opusieron a la existencia de la primera Comisión; también operaron para que la creación de la segunda, que además tendría atribuciones mucho más amplias, no llegara a materializarse.

El segundo período (1973-1975) se inicia con la promulgación de la Ley General de Población en diciembre de 1973. Este instrumento, que coordina la Secretaría de Gobernación a través del Consejo Nacional de Población, tiene o puede tener implicaciones en todos los órdenes del desarrollo socioeconómico del país. El primero de sus trece objetivos pretende "adecuar los programas de desarrollo económico y social a las necesidades que planteen el volumen, estructura, dinámica y distribución de la población". ${ }^{77}$

Otros objetivos se refieren a la planificación de ciudades, la migración interregional de población, reducir la dispersión de población, etc. En 1974 se creó el Consejo Nacional de Población como instrumento para cumplir los objetivos de la Ley.

La Secretaría de la Presidencia es la dependencia del Ejecutivo que, de acuerdo con sus atribuciones, ha venido multiplicando en forma acelerada, en particular en este segundo período, las medidas de fomento regional. A principios de 1974 empezó a extenderse el interés por la crea-

\footnotetext{
76 Dirección General de Programación y Descentralización Administrativa, op. cit., pp. 89-94.

77 Ley General de Población, Art. 3\%, inciso I.
} 
ción de Comités Promotores del Desarrollo Socioeconómico estatal. A mediados de ese año se habían instalado comités en nueve estados más y con atribuciones más amplias que las originales. En enero de 1975 se crearon los Comités que faltaban para cubrir todas las entidades federativas excepto el Distrito Federal. Una de las finalidades más importantes de estos mecanismos institucionales es la de elaborar programas de inversiones federales a nivel de entidades federativas para proporcionar al Ejecutivo mejores elementos de juicio para la estructuración del presupuesto del gasto público federal sectorial. Así, también los Comités se responsabilizan de la coordinación de las inversiones de las diferentes dependencias de gobierno; de la formulación de planes de desarrollo socioeconómico y de otras funciones.

Con objeto de coordinar las acciones de los Comités Estatales y apoyarlos técnicamente se creó, a principios de 1974, la Dirección General de Desarrollo Regional en la Secretaría de la Presidencia. Esta Secretaría, a partir de este momento, se ha propuesto crear los mecanismos de coordinación entre los esfuerzos nacionales y regionales y entre los regionales y estatales, con objeto de reducir el desperdicio de recursos escasos y mantener la tasa de crecimiento económico nacional. ${ }^{78}$ Para el efecto, el gobierno federal creó en enero de 1975 la Comisión Nacional de Desarrollo Regional. Integrada por los subsecretarios de todos los ministerios del gobierno y los directores de organismos descentralizados y empresas de participación estatal y presidida por el Secretario de la Presidencia, tiene como función básica elaborar planes de desarrollo para regiones que comprenden dos o más entidades federativas. De esta forma se pretende darle dimensión espacial a los lineamientos sectoriales de programación, como también coordinar las inversiones públicas federales entre sí y compatibilizarlas con las estatales, para que las acciones de los Comités Promotores del Desarrollo Socioeconómico de los estados sean congruentes con las políticas generales de desarrollo regional y nacional. En pocas palabras, el gobierno federal, a través de la Secretaría de la Presidencia, ha creado una serie de mecanismos de coordinación a los niveles nacional, regional y estatal, para dar congruencia a las decisiones que tomen organismos de gobierno que actúan a dichas escalas. La primera decisión de la Comisión fue la adopción oficial de la regionalización del país en nueve regiones, cada una de las cuales está formada de dos o más entidades federativas.

Esta regionalización será la base sobre la cual operará la mencionada Comisión Nacional de Desarrollo Nacional.

Por último, se debe hacer mención de la importante colaboración prestada por un grupo de asesores técnicos de la Organización de las Naciones Unidas (CEPAL-ILPES) a la Secretaría de la Presidencia en materia regional durante los últimos tres años.

78 Ibid. 


\section{XII. "EvaluacróN" DE LAS MEdidas}

Después de mencionar tan impresionante número de medidas, puestas en vigor a partir de 1970 con la intención de descentralizar la industria y fomentar el desarrollo regional, y de reconocer no sólo la cantidad sin precedentes de instrumentos de esta índole, sino en particular su alcance real y potencial para racionalizar las acciones del sector público a escala regional y estatal, surge la duda. ¿Iremos, ahora sí, por el camino correcto? ¿Vamos en la dirección acertada? Las preguntas, teóricamente hablando, y si deseamos rigor en las respuestas, son casi imposibles de contestar. Para ello necesitaríamos y, aún así no existe garantía, conocer en detalle la dinámica causa-efecto de las principales fuerzas sociales que han intervenido y que lo harán en el futuro próximo en el desarrollo del país y del mundo capitalista dada nuestra dependencia. En otras palabras, requerimos saber qué actores intervienen en el desarrollo social, económico y político de México, qué papeles han jugado, cómo se interrelacionan sus roles, por qué motivos lo han hecho y que consecuencias ha tenido. Además, las relaciones causales pueden cambiar en el tiempo; por lo mismo, los efectos que se logren de aplicar una misma medida de gobierno en dos momentos distintos, pueden ser diferentes. Pero la base de este razonamiento está en que, por definición, no existe consenso de intereses en las sociedades, particularmente en las de los países capitalistas, dónde las distancias sociales son mayores. Por lo tanto, lo que pudiera ser una estrategia acertada para ciertos grupos sociales no lo será para otros. Por último, como se dijo antes, no se tiene información suficiente sobre indicadores como empleo generado o como migración retenida, aumentos absolutos y relativos en el ingreso per capita regional, etc,. que expresen efectos de la aplicación de estos instrumentos regionales. Aunque todo este conjunto de medidas gubernamentales pueden y seguramente, tal y como lo establecen las funciones de la Comisión Nacional de Desarrollo Regional y de los Comités Estatales Promotores del Desarrollo, se van a tratar de estructurar para establecer la conexión programática país-región-estado, actualmente no se tienen objetivos suficientemente concretos, para ser medibles. Por ejemplo, cuando se logren reducir las disparidades regionales, $i$ en qué aspectos y en qué medida podremos decir que la estrategia ha sido efectiva? $\mathrm{Y}$, ¿en qué porciento habrá que reducir la macrocefalia de población urbana o nacional o de producción industrial, para aseverar que las medidas empleadas han sido eficaces?

Haciendo a un lado de momento cuestiones debatibles como algunas de las planteadas, así como otras que no creemos gratuitas ni ociosas de formularse, como por ejemplo: ies la macrocefalia un problema de primera jerarquía o un falso problema como afirman Singer y otros autores, ${ }^{79}$ nos proponemos cerrar este ensayo con una serie de cuestiones y

79 En cierto modo lo dijimos en la primera parte. Aquí sólo queremos fortalecer tal argumento con cuestionamientos hechos en otros países. Véanse por ejem- 
breves comentarios sobre algunas de las medidas implantadas y sobre su conjunto, con base en los antecedentes de que disponemos sobre la planeación en México.

\section{Posibles incompatibilidades}

La falta de una política general de desarrollo regional según los criterios establecidos, no obstante la clara expresión del lineamiento básico de la estrategia a seguir establecido por el Presidente (simultáneamente crecer y redistribuir) da la impresión que se suscitan incompatibilidades entre algunas de ellas, en particular durante el primer período (19701973). Es difícil que esto no ocurra ante lo numeroso de las medidas, su distinta naturaleza, administradas por distintos organismos del sector público en los cuales las decisiones son tomadas por funcionarios que no necesariamente representan los mismos intereses personales ni de grupo. ${ }^{80}$ Las posibilidades de evitar la multiplicación de medidas que se contrarrestan y contradicen se reduce aún más si tomamos en cuenta la vigencia de un elevado número de instrumentos existentes y creados por esta administración que, sin tener objetivos explícitos de descentralización industrial o desarrollo regional, tienen indiscutiblemente fuertes efectos espaciales. Tal es el caso de la Ley Federal de Aguas, la Ley de Reforma Agraria, la construcción de caminos, etc. Es cierto que el gobierno está haciendo esfuerzos por reducir la inefectividad y baja productividad de la parte del sector público constituida por organismos descentralizados y de participación estatal, a través de la nueva ley de control y vigilancia de la Secretaría del Patrimonio Nacional. ${ }^{81}$ Esto puede ayudar en la coordinación administrativa del sector público, pero no creo que haya podido o pueda evitar que se formulen objetivos y lleven a cabo acciones -ya sea por motivos políticos o por la complejidad y escasa coordinación del sistema administrativo del país- que se contrarresten o hasta se opongan a la estrategia general de desarrollo regional y fomenten aún más la centralización del sistema.

Como ejemplo podemos mencionar las incompatibilidades que se presentan actualmente entre todos aquellos programas y proyectos del sector público y privado, dentro de la ZMCM - en el Distrito Federal y el Estado de México- o fuera de ella, ya sea para ayudar a resolver sus comple-

plo, Singer, "Urbanización, dependencia y marginalidad en América Latina", op. cit., y Ronaldo Ramírez, op. cit.

so "Junto con los intereses de los organismos públicos están los propios intereses de los funcionarios y políticos que en muchos casos se opondrían política e ideológicamente a una orientación definida de las acciones políticas del Estado. La multiplicidad de los intereses de los organismos públicos, y de los propios cuadros dirigentes dentro del Estado, imposibilitan la adopción de una línea política fundamental que no sea la de autodefensa frente a las presiones populares." Manuel Camacho, loc. cit., p. 96.

81 Proel, op. cit., p. 666. 
jos problemas, o bien porque conviene a intereses económicos y políticos de muy variada naturaleza que van desde el "cacique urbano" de una colonia proletaria, hasta el especulador urbano y los más altos funcionarios del gobierno. Más específicamente, ¿cómo es posible evitar que el gobierno federal no intente resolver los problemas del abastecimiento del agua a la ZMCM, el de energía eléctrica, el del desalojo de las aguas negras, el de la contaminación atmosférica, el del tránsito de vehícuos, ${ }^{82}$ etc., seguramente a un elevado costo económico, no sólo para la propia zMCM y los contribuyentes que en ella residen, sino para el país en su conjunto, cuando obras como las del sistema metropolitano requieren de créditos externos? Lo anterior es una clara ilustración del dilema que plantea, la simultaneidad del crecimiento general y de la redistribución territorial. Independientemente de que frenar o aún reducir la macrocefalja es condición necesaria, pero no suficiente, para redistribuir socialmente el ingreso, se requiere disponer e invertir muchos más recursos en la periferia que ahora se utilizan en el centro. Pero resulta que el Distrito Federal acepta y está dispuesto a contribuir al llamado nacional y estatal para descentralizar la industria, siempre y cuando no se le descapitalice, o sea que no pierda, entre otras cosas, fuentes de empleo, pues de lo contrario perdería, obviamente, poder político y tendría que enfrentarse a serios conflictos sociales. Por otro lado, el estado de México, que hasta el momento no ha llegado a coordinar objetivos, programas, ni acciones para la $\mathrm{ZMCM}$-imagino que por conflictos de intereses a distintos niveles sociales y políticos entre el Distrito Federal, el estado de México y la Federación- siente, justificadamente o no, que le ha servido de válvula de escape a muchos de los problemas que han desbordado el Distrito Federal. Por esta razón y por que el estado de México tiene todavía zonas sumamente pobres, interpreta la descentralización industrial de modo particular, en el sentido de colaborar a frenarla en los municipios metropolitanos de 1960 y algunos incorporados en $1970 .{ }^{83}$ Al mismo tiempo, cree tener necesidad y presentar factores de localización favorables a la industrialización en municipios no metropolitanos como Santiago Tianguistengo y aun metropolitanos, como Cuautitlán, relativamente cerca del límite norte del área urbana de la ciudad de México. Estas acciones inevitablemente fomentarán el crecimiento de la $\mathrm{ZMCM}$ en territorio del estado de México. Estas acciones inevitablemente fomentarán el crecimiento a la zMCM en territorio del estado de México.

Por último, distintas dependencias del ejecutivo federal, en su deseo por resolver algunos de los problemas de la metrópoli, realizan proyectos y obras que en lugar de contribuir a la descentralización, pienso que la frenan. A este tipo de medidas corresponde la construcción, tanto en el Distrito Federal como en el estado de México, de submetrópolis o de un

82 A las presiones que estos problemas ejercen sobre el gobierno, Camacho les llama, "las presiones del proceso modernizador". M. Camacho, loc. cit., p. 90.

83 Luis Unikel, La dinámica del crecimiento de la ciudad de México, Fundación para el Estudio de la Población, México, 1972. 
anillo periférico externo que además de los enormes recursos que requiere su construcción y que supuestamente deben invertirse en la provincia más pobre, contribuye a la concentración del ingreso y fomenta la expansión física de la ZMCM y la centralización.

De ser correcta o lógica esta línea de pensamiento, surgen varias cuestiones de difícil respuesta, pero importantes en relación a la estrategia que se sigue o a la que debe implantarse con respecto a la macrocefalia y al desarrollo regional: a) ¿Cómo se podría reducir la macrocefalia demográfica y económica si todo parece indicar que a pesar de las evidentes deseconomías de la ZMCM, las fuerzas sociales que intervienen en su crecimiento (a los que les conviene y que no tienen, o piensan que no tienen otra alternativa que quedarse en la ZMCM, los que desean que la ZMCM siga proveyendo amplias oportunidades a la explotación del capital, tierra y mano de obra, así como a los que en el campo no tienen otra salida que emigrar) siguen y seguirán operando mientras no ocurran cambios estructurales que modifiquen la magnitud y sentido de tales fuerzas? ${ }^{84}$ b) por lo tanto, parece que no será posible reducir la macrocefalia sin: i) imponer medidas desalentadoras ${ }^{85}$ a la inversión de capital

84 Difícilmente podemos saber si la tasa de crecimiento de la ZMCM de 1970 1975 se ha frenado o no, y de qué magnitud ha sido en caso afirmativo, pero la evidencia directa parece apuntar que la desaceleración de su crecimiento que, inevitablemente se estará produciendo, no será considerable o suficiente para que disminuya o aún se frene la macrocefalia demográfica. Para que sucediera esto último, tomando como buena la proyección de población para 1980, de 72 miIlones, la AUCM debería alcanzar 12.3 millones de habitantes, o sea 1.3 millones menos que la menor de las estimaciones que la proyección de la tendencia histórica señala. Véase Luis Unikel, Crescencio Ruiz Chiapetto y Gustavo Garza, op. cit., Cap. IX. Esto implica que el incremento medio anual del área urbana de la ciudad de México (AUCM) disminuye del $5.2 \%$ de $1960-1970$ al $3.8 \%$, un $27 \%$ menos. Significa que, si suponemos que la tasa de crecimiento natural baje un $10 \%$, de $3 \%$ al $2.7 \%$, el incremento medio anual del saldo neto migratorio, sería del $1.1 \%$-50\% menos que de 1960 a 1970-, y éste alcanzaría un volumen aproximado de 1.1 millones de personas contra cerca de 1.5 millones. No obstante lo grueso de estas estimaciones, dan idea de que es difícil que ocurra mientras las oportunidades para generar empleo adicional en el campo se mantengan escasas, la selectividad para migrar disminuya, y la ciudad de México continúe satisfaciendo algunas de las necesidades de la población migrante. La aseveración anterior es, en parte, apoyada por la del estado de México que revela la existencia de poderosas fuerzas centralizadoras, y que no se visualizan de momento ciudades o regiones que pudieran interceptar los flujos migratorios al Distrito Federal. Véase Instituto de Desarrollo Urbano y Regional, Urban and Regional Planning, Summer Research Proyect, Report 3: A Gravity Model of Migration, Flow Division and Flow Creation for Mexico, 1974.

85 Concuerdo con Yates en que el establecimiento de controles o de medidas prohibitivas para frenar la inversión en la zMCM podría tener efectos contraproducentes en un sistema sociopolítico como el de México. Yates considera "...mucho más eficaz, equitativos para las empresas y menos peligroso en otros aspectos, utilizar medidas desalentadoras...", por ejemplo "...hacer que la industria contribuya en mayor proporción a los costos sociales reales del Valle de México y entonces cada empresa optará por la localización que más le convenga". Yates, 
privado de cierto monto y en determinadas actividades económicas y en ciertas partes de la ZMCM, así como del Valle de México; ii) ejercer un control efectivo de las inversiones públicas que se realicen en la ZMCM y fuera de ella, pero en su beneficio, reduciendo y posponiendo una serie de obras de beneficio social que afectará principalmente a la población de menores ingresos; iii) eliminar los subsidios federales al costo de la vida; ${ }^{86} i v$ ) hacer efectivo el cumplimiento de las leyes de contaminación atmosférica y del agua afectando fuentes de empleo industrial, comercial y servicios, en particular las medianas y pequeñas, por la imposibilidad económica de cumplirlas o por el aumento de salarios que suscitaría cobrar el costo económico real y más aún el social, de los servicios públicos y de la vivienda hoy en día de renta congelada; v) relocalizar fuera del Valle de México importantes funciones político-administrativas federales; vi) desplazar a un segundo plano varios de los objetivos de crecimiento de la ZMCM sin que surja una confrontación de intereses nacionales y metropolitanos.

Por razones ya mencionadas, no hay duda que una política que cumpliera parcial o totalmente con algunas de estas medidas tropezaría con la hostilidad del público y encontraría enormes resistencias políticas. ${ }^{8 \top}$ Esto, que fue aseverado por Yates en 1960, tiene hoy día aún mayor vigencia. Sus recómendaciones de hace quince años, una variante más tenue de la política regional británica de: incentivos-periferia, controlescentro (en México sería de medidas desalentadoras en el centro), en términos generales siguen teniendo validez. Sin embargo, la mayor duda que surge después de no haberse hecho casi nada al respecto durante dos lustros (1960-1970) y algo en el tercero, es en cuanto a la viabilidad económica y política que tiene la estrategia. Preocupa: el posible impacto negativo que a corto plazo pudiera tener en el crecimiento económico nacional; el deterioro que seguramente experimentaría la infraestructura física de la $\mathrm{ZMCM}^{88}$ el que no convenga mejorar la funcionalidad de la ZMCM a través de la institucionalización entre el Distrito Federal, el estado de México y el gobierno federal, de los objetivos, planes y programas de acción a nivel metropolitano, de modo que se reduzcan los desperdicios de recursos, las molestias a los residentes y una serie de deseconomías que provoca la presente desconexión Distrito Federal-estado de México.

op. cit., p. 249. Esta es precisamente una de las medidas propuestas por el GEPE para el mismo propósito. Véase GEPE, op. cit.

86 Ya en 1960, Yates pensaba que los subsidios federales al transporte, a los alimentos y a la vivienda no se justificaban. Yates, op. cit., p. 250.

87 Ibid., p. 255.

88 El caso extremo es el de La Habana, en que la disminución radical del gasto público y las inversiones para el mantenimiento y rehabilitación de la ciudad ha propiciado un serio deterioro físico. Esta política premeditada ha posibilitado al gobierno disponer de mayores recursos para el desarrollo del resto del país, así como de un elemento de juicio adicional a los incentivos que ofrece fuera de La Habana. 
No existe un dilema inevitable entre la expansión económica y la redistribución del ingreso, teóricamente hablando, pero es materialmente imposible de realizar en la práctica, en particular si se trata de la redistribución del ingreso personal. Al respecto, México tiene una experiencia aleccionadora, la del programa de cuencas hidrológicas antes mencionado. En el caso de una de ellas, la del Tepalcatepec -que se puede generalizar a todas- no hay duda que las inversiones realizadas generaron riqueza y aumentaron el ingreso per capita de la región, debido a que han "... representado un claro beneficio para el desarrollo económico nacional". Además, "la estrategia ... [ha consistido] en subsidiar industrias y no regiones, [lo cual] ... no implica necesariamente un mejoramiento en la distribución del ingreso dentro de estas áreas". “... En el caso de la cuenca del Tepalcatepec, una parte considerable del aumento de la producción fue financiada por grupos que emigraron de partes más ricas del país. Sus recursos y experiencia ayudaron a aumentar la alta tasa de crecimiento de la región, pero también explica la concentración tan grande del ingreso que se observa actualmente." 89

¿Acaso no estaremos repitiendo esta experiencia al subsidiar a las industrias que se ubiquen en aquellas ciudades que se seleccionen como polos de desarrollo o en los municipios de las zonas II y III, según el decreto de 1972, cercanos a las grandes ciudades? ¿Cómo es posible evitar que el ingreso personal se concentre en las regiones que reciben mayor participación del gasto público federal con este tipo de política redistributiva, si en ella el gobierno estimula predominantemente a aquellos que tienen los recursos necesarios para financiar el crecimiento, o que pueden tener acceso al crédito? ${ }^{90}$ Dicho en otros términos, ¿cómo se puede evitar el dilema entre la redistribución territorial del ingreso y la personal, si no es a través de grandes subsidios como sería el ofrecimiento directo de recursos productivos a los marginados, a las personas que carecen de medios para producir y vender bajo condiciones comerciales, a quienes carecen de educación y experiencia, y que no son sujetos de crédito? Otorgar este tipo de subsidios casi seguramente incidiría en sentido negativo, por lo menos a corto plazo, en el crecimiento nacional. Algo semejante se plantearía espacialmente, entre las regiones relativamente pobres y ricas, si el gobierno federal concede a las primeras una mayor proporción del gasto público productivo y de beneficio social para poder cerrar la brecha entre ellas. Aunque no creo que se llegue a este extremo, por las crecientes presiones políticas que ejercerían los estados

89 Este es el título más preciso de una de las bases principales para la política económica regional que proponen conjuntamente la Secretaría de la Presidencia y el equipo de investigación ILPES-CEPAL de Naciones Unidas, en el estudio más serio y técnicamente elaborado que se haya realizado hasta ahora en México.

90 Ibid., y A. Gilbert y D. Goodman, Regional Income Disparities and Economic Development: A Critique of Current Opinions, Ponencia presentada en el Instituto Británico de Geógrafos, Universidad de Oxford, enero de 1975, p. 30. 
más avanzados, que son a la vez los más politizados y los que, paradójicamente, registran mayor oposición al gobierno, ${ }^{01}$ es más factible que suceda a través del descubrimiento y utilización de recursos naturales inexplotados. Además, cumplir la estrategia para reducir la distancia entre las regiones más pobres y el Valle de México, implicaría, probablemente, frenar el crecimiento de las que se han venido acercando, como el noroeste y el norte, y seguramente también el de la ZMCM.

Los planteamientos anteriores dan pie para pensar que dentro del sistema capitalista no es posible evitar el conflicto entre el crecimiento económico y la redistribución personal del ingreso, especialmente si se emplean planes indicativos. El dilema entre el crecimiento económico y la redistribución territorial del ingreso es menos acentuado; sin embargo, es probable que al principio de tal redistribución se observará mayor concentración del ingreso inter e intrarregional. Simultáneamente, se cerrará la brecha entre las regiones más desarrolladas y se abrirá la de éstas con las más rezagadas. De esta manera, los recursos de capital de los inversionistas del centro podrán beneficiarse en la periferia de la política de desarrollo regional posiblemente aun más que en la $\mathrm{ZMCM}$, aprovechando los múltiples y sustanciales subsidios del gobierno en ubicaciones como las de algunos municipios de las zonas II y III (decreto 1972) que ya son metropolitanos o están cerca de ellos. Esto contribuirá a su vez a acentuar la desigualdad intra-urbana del ingreso en la ZMCM, al disminuir la generación de empleo y posponerse las inversiones de beneficio social. Asimismo, será necesario establecer controles a la reinversión regional; de lo contrario puede también propiciar una mayor concentración de capital en la zмcM.

El propósito de las preguntas anteriores no ha sido un ejercicio ocioso ni gratuito, sino el deseo de hacer ver a quienes están planteando la política, cuestiones que probablemente ya saben, pero que hasta ahora no han planteado en los escritos disponibles : ${ }^{92}$ la factibilidad de que a) se realicen las medidas que se proponen para llevar a cabo la descentralización industrial y el desarrollo regional $\mathrm{y}, b$ ) que en caso afirmativo se cumplan los objetivos básicos del nuevo modelo económico (expansión económica y redistribución del ingreso).

En suma:

1) Es indiscutible que en la presente administración se ha puesto en vigor un número sin precedente de medidas tendientes a la descentralización industrial y al desarrollo regional, entre las cuales se incluyen la creación de organismos y mecanismos institucionales que tienen por objeto aumentar la comunicación entre los gobiernos nacional y estatal, y tratar de hacer compatibles los objetivos de la estrategia nacional (crecimiento con redistribución) y la distribución del gasto público nacional

91. Rafael Segovia, loc, cit.

92 Véase, Gobierno de México y Naciones Unidas, Bases para la política económica regional (parte I a IV del proyecto de desarrollo regional y urbano de México), México, 1974. 
con los programas de inversiones estatal y regional. Que se han intentado algunas medidas de reforma administrativa, que se observa que la creciente preocupación por estos problemas se ha traducido en estudios técnicamente más serios y detallados patrocinados por el propio sector público (Secretaría de la Presidencia), así como en recomendaciones cada vez de mayor alcance político-administrativo. En pocas palabras, pienso que se están planteando las bases para que México pueda contar por primera vez con una política nacional de desarrollo regional, de acuerdo a los criterios establecidos anteriormente.

2) Sin embargo, los estudios, y los planes y programas que han resultado de ellos, se están planteando o es la impresión que se capta, en el "vacío social", en cuanto a que no se analiza a fondo la viabilidad económica y sociopolítica tanto de los objetivos formulados como de las medidas que se están implantando para cumplirlos.

3) Los cambios institucionales que se están gestando aseguran únicamente el uso de la planificación como instrumento, como técnica. El plan tendrá, en el mejor de los casos - pues existen innumerables factores sociopolíticos y económicos que se oponen - la posibilidad de ser ejecutado. Pero, atacar las causas que generan las desigualdades territoriales del ingreso y en particular las personales, exige la realización de cambios que rebasan el marco administrativo.

4) Ello significa que la planificación indicativa - la cual todavía no se ha experimentado en México de modo integral y que incluya tanto al sector público como al privado- es insuficiente para lograr los objetivos formulados; está imposibilitada para resolver los problemas de fondo. Se requiere que el gobierno no sólo asuma el papel de proporcionar incentivos a la iniciativa privada en localizaciones periféricas para garantizar la redituabilidad de sus inversiones a efecto que se generen los ambiguamente llamados "polos de crecimiento o desarrollo", sino que debe asignar partes considerables de los recursos económicos, tecnológicos y culturales del país hacia los grupos de población que están fuera de la estructura actual del control político y económico.

5) Para intentar redistribuir el ingreso personal no es posible depender de la difusión del desarrollo del centro a la periferia, que supuestamente generan los polos de crecimiento, pues la experiencia en América Latina y aún en Europa muestran su escasa efectividad. Sé requerirán medidas adicionales orientadas directamente a la generación de empleo y a mejorar las condiciones de vida de la población de menores ingresos. De lo contrario, se agudizará la concentración de la riqueza, pero ahora en un mayor número de sitios. Esto posiblemente alivie las presiones que actualmente ejerce la periferia sobre el centro, o difiera una confrontación seria, pero es difícil esperar que mejore de manera significativa el ingreso regional o su distribución.

6) En vista de lo anterior, es necesario que el gobierno sea más explícito y detallado, aunque ello implica un serio compromiso social y político, en los objetivos de la política que desea llevar a cabo, tanto en 
lo que se refiere al crecimiento económico nacional como, y en particular, en lo relativo a la redistribución del ingreso.

7) Por último, las medidas que ha puesto en vigor el actual gobierno, no obstante que intentan corregir los desequilibrios regionales inherentes a las contradicciones del sistema económico, sólo lo pueden hacer formalmente. Para llevarlo a cabo efectivamente se requieren cambios estructurales que dadas las actuales circunstancias sociopolíticas se cree que tienen escasa viabilidad de realizarse. 